\title{
Uncertainties of LAI estimation from satellite imaging due to atmospheric correction
}

\author{
T. Mannschatz ${ }^{\text {a,b,d, },}$, B. Pflug ${ }^{\text {e }}$, E. Borg ${ }^{\text {f }}$, K.-H. Feger ${ }^{\text {d }}$, P. Dietrich ${ }^{\text {b,c }}$ \\ a United Nations University, Institute for Integrated Management of Material Fluxes and of Resources (UNU-FLORES), Ammonstraße 74, 01067 Dresden, Germany \\ ${ }^{\mathrm{b}}$ Helmholtz Centre for Environmental Research (UFZ), Department of Monitoring and Exploration Technologies, Permoserstraße 15, 04318 Leipzig, Germany \\ c Eberhard Karls University Tübingen, Tübingen, Germany \\ d Technische Universität Dresden, Institute of Soil Science and Site Ecology, Pienner Straße 19, 01737 Tharandt, Germany \\ e German Aerospace Center (DLR), Remote Sensing Technology Institute, Photogrammetry and Image Analysis, Rutherfordstraße 2, 12489 Berlin, Germany \\ ${ }^{\mathrm{f}}$ German Aerospace Center (DLR), German Remote Sensing Data Center, National Ground Segment, Kalkhorstweg 53, 17235 Neustrelitz, Germany
}

\section{A R T I C L E I N F O}

\section{Article history:}

Received 7 November 2013

Received in revised form 7 July 2014

Accepted 10 July 2014

Available online xxxx

\section{Keywords:}

LAI estimation

Hydrological modelling

Uncertainty analysis

Sensitivity analysis

Satellite imaging

Atmospheric correction

ATCOR

\begin{abstract}
A B S T R A C T
Leaf area index (LAI) is a plant development indicator that as an input parameter strongly influences several relevant hydrological processes represented in Soil-Vegetation-Atmosphere-Transfer (SVAT) models. Generally, temporal measurement or monitoring of LAI is challenging or even impossible in remote areas. High-temporal resolution remote sensing imaging can be used to estimate LAI from vegetation indices calculated from band ratios. This paper shows the sensitivity of LAI estimation from satellite imaging to atmospheric correction (with ATCOR) and evaluates the effects of LAI uncertainty on water balance modelling. LAI as a SVAT model input parameter was estimated based on the empirical relationship between field measurements, and the vegetation indices NDVI (Normalized-Difference Vegetation Index), SAVI (Soil-Adjusted Vegetation Index) and SARVI (Soil-Atmosphere Resistant Vegetation Index) for six RapidEye images obtained between 2011 and 2012. In summary, we found that the ATCOR parameter 'visibility' has the strongest influence on LAI estimation. Likewise, atmospherically corrected successive images gathered from around the same time period had low LAI differences (mean absolute difference of $0.09 \pm 0.08$ ) on overlapping image areas. This uncertainty is negligible in SVAT modelling in most cases, thereby allowing mosaicked successive atmospherically corrected images to be used. We showed that LAI uncertainties arising from atmospheric correction (ATCOR 3 ) can translate into small (LAI $\pm 0.1 \approx$ evapotranspiration \pm $0.9 \%$, interception $\pm 2.5 \%$, evaporation $\pm 3.3 \%$, transpiration $\pm 0.7 \%$ ) to moderate $(\mathrm{LAI} \pm 0.3 \approx$ evapotranspiration $\pm 4.1 \%$, interception $\pm 7.5 \%$, evaporation $\pm 9.9 \%$, transpiration $\pm 2.4 \%)$ SVAT model uncertainty.
\end{abstract}

(C) 2014 Elsevier Inc. All rights reserved.

\section{Motivation}

Knowledge of the water balance is essential in land management; especially, for instance, in the case of large land use changes (such as converting grassland to forest plantations). Since water balance processes are complex, Soil-Vegetation-Atmosphere-Transfer (SVAT) models are applied to simulate how vegetation affects the water balance and energy fluxes. These models additionally help us to obtain a better understanding of hydrological processes by simulating different land use and climate change scenarios. Vegetation affects the water and energy balance via transpiration, water uptake, interception, evaporation

\footnotetext{
* Corresponding author at: UNU-FLORES, Ammonstraße 74, 01067 Dresden, Germany. Tel.: +49351 89219370

E-mail address: mannschatz@unu.edu (T. Mannschatz).

URL's:E-mail addresses: http://orcid.org/0000-0002-8467-7363 (T. Mannschatz), http://orcid.org/0000-0002-4626-9393 (B. Pflug).
}

(Arora, 2002) and water storage within the plant (Cermák, Kucera, Bauerle, Phillips, \& Hinckley, 2007). Vegetation development is highly dependent upon seasonal variations (e.g. water availability, temperature). In contrast, the annual plant development stages are often assumed to be stable for longer periods than they are in reality for the purposes of hydrological and SVAT modelling (Arora, 2002). Furthermore, in many cases, information concerning specific plant parameters is taken from relevant literature and not from actual measurements. Evapotranspiration is a dynamic process that depends on plant conductance, size and arrangement of the stomata, as well as the amount of leaves. These plant-dependent processes make vegetation a dynamic SVAT model component. An indicator that can be used for evapotranspiration prediction is the leaf area index (LAI), which is represented by the ratio of the total one-sided area of photosynthetic tissue and unit ground surface area (Zheng \& Moskal, 2009). Thus, evapotranspiration modelling is affected by temporal variation and absolute LAI values (Metselaar, van Dam, \& Feddes, 2006). Generally, the measurement or monitoring of LAI is challenging due to the high spatial and temporal variability of vegetation growth and development. Furthermore, 
destructive or indirect ground-based measurement methods are typically time-consuming and the information obtained only represents local scale (Bréda, 2003). The increasing availability of high-temporal resolution remote sensing data is a promising tool for monitoring LAI development over the course of the year. First of all, this allows more dynamic SVAT parameterisation in remote areas and secondly, makes it possible to model on larger scales (Yao, Liu, \& Li, 2008). A simple and therefore often applied approach that can be used for retrieving LAI data from remote sensing measurements is based on empirical relationships between vegetation indices (VI) and LAI field measurements (Zheng \& Moskal, 2009). Several studies have shown that the relationship between LAI and VI can be expressed as an exponential function (e.g. Du et al., 2011; Glenn, Huete, Nagler, \& Nelson, 2008; Haboudane, 2004; Viña, Gitelson, Nguy-Robertson, \& Peng, 2011; Wiegand \& Richardson, 1990). The most common vegetation indices are calculated using spectral band ratios from satellite images. NDVI (Normalized-Difference Vegetation Index) is probably the most used VI in ecological studies (Glenn et al., 2008; Haboudane, 2004; Kerr \& Ostrovsky, 2003; Pettorelli et al., 2005). SAVI (Soil-Adjusted Vegetation Index) accounts for soil influences on reflectance and SARVI (Soil-Atmosphere Resistant Vegetation Index) additionally accounts for atmospheric influences. Thus, SARVI is assumed to be the VI that is least sensitive to atmospheric correction. Nevertheless, the estimation of LAI from VI time series requires true reflectance values of the land surface, which helps ensure comparability between the different satellite images. However, measured radiation at the sensor is non-linearly influenced by different atmospheric compositions (e.g. water vapour, dust particles), solar illumination, terrain topography, and satellite configuration (e.g. type of sensor, viewing angles) (Richter \& Schläpfer, 2013). Holzer-Popp et al. (2002) investigated the potential influence of important atmospheric parameters (ozone, water vapour, Rayleigh scattering, aerosol scattering) on spectral reflectance of NOAA-AVHRR and derived NDVI data. They found NDVI variation ranges (mean bare soil, deciduous forest) of $+0.013-0.044$ for ozone (250-500 D.U.), $-0.024-0.079$ for water vapour $\left(0.5-4.0 \mathrm{~g} / \mathrm{cm}^{2}\right)$, $-0.061-0.177$ for Rayleigh (1013.25 hPa), and $-0.014-0.213$ for continental aerosols $\left(\tau_{550 \mathrm{~nm}}=0.05-0.8\right)$. Since the atmospheric and observation conditions change quickly, satellite images of different time steps are not necessarily comparable. For this reason, atmospheric correction should be applied to satellite images in order to minimise atmospheric and observation geometry influences on the derivation of physical earth surface parameters, which can occur during image capture (Hadjimitsis et al., 2010). The atmospheric correction algorithm aims to minimise atmospheric and observation geometry influences and to convert the original digital numbers (DN) measured by the sensor to 'true earth' surface reflectance values (Richter, Schläpfer, \& Müller, 2006). After application of the algorithm, atmospherically corrected satellite images, together with their data products (e.g. VI, LAI), should be comparable.

This paper presents and discusses the effects of diverse parameterisation of atmospheric correction models on VI retrieval and any impacts these have upon LAI estimation and SVAT model output. To this end, we: (i) describe the study area, satellite data, and image preprocessing, and (ii) systematically atmospherically correct the satellite images and test the sensitivity of ATCOR for input parameter variation. Subsequently, (iii) different VI values are calculated for our atmospherically-corrected images, (iv) a LAI retrieval model from LAI ground measurements is established, and $(\mathrm{v})$ the retrieved LAI values from all images are compared, in order to understand their variability due to the atmospheric processing scheme used. We (vi) evaluate uncertainties of LAI estimation due to atmospheric correction, comparing LAI for the overlapping area of two pairs of successive images. Finally, (vii) we present an overview of the importance of LAI for SVAT modelling, including a simple LAI sensitivity analysis. This study gives an impression of potential error propagation in this process, from the initial raw satellite image right up to the final LAI product and SVAT model output.

\section{Study site}

The study site is located in NE-Brazil in the state of Bahia (Fig. 1). It is a bamboo (Bambusa vulgaris) plantation of approximately $8 \mathrm{~km}^{2}$ and is operated by Penha Papeis e Embalagens. This plantation has existed and been in operation since the mid-1970s. Bamboo is planted in rows with an approximate separation distance of $3 \mathrm{~m}$ to $6 \mathrm{~m}$. In general, bamboo is harvested after 3 years and continues growing rapidly from the stump after harvest. The plantation area is divided into fields that are harvested at different times. Due to this fact, bamboo plants at different growth development stages ( $0-3$ years) are present here. The designated site for our detailed investigation (Fig. 1) includes a waste disposal area (includes non-vegetated areas) that is made up of construction material (e.g. sand, gravel) and is surrounded by an approx. 40-100 m vegetation strip of mature bamboo (ca. $15 \mathrm{~m}$ height). Located adjacent to our investigation area are some bamboo fields with crops at growth stage approx. 6-7 months (February 2012) with plant height of 2-4 m. Secondary forests are located at distances of about $120 \mathrm{~m}$ (south), $250 \mathrm{~m}$ (west), and $250 \mathrm{~m}$ (north-east) from the waste disposal area. The climate is designated by Köppen-Geiger as being an Af climate (equatorial fully humid), with precipitation levels for the driest month being: $P_{\min }>60 \mathrm{~mm}$ (Kottek, Grieser, Beck, Rudolf, \& Rubel, 2006). The mean annual precipitation is approx. $1600 \mathrm{~mm}$ (1945-2011), with a rainy season from March to August, a dry season from September to February and mean annual temperature of $24{ }^{\circ} \mathrm{C}$ (CEPLAC climate station). According to the Brazilian Soil Classification system, the plantation is located on clayey vertisols with high iron-oxide content (Embrapa, 2006).

\section{RapidEye images and ATCOR description}

The RapidEye satellites deliver images over 5 spectral bands: blue, green, red, red edge and near infrared (NIR) wavelengths (RapidEye, 2012). The RapidEye satellite constellation has a revisit time of twice daily. Frequent coverage of the land surface is especially important in humid tropical regions, where generally high levels of cloud prevail. RapidEye level 3A products are used for these investigations. The images are given as 25 by 25 kilometre tiles, which are referenced to a fixed, standard RapidEye image tile grid system. Each of the tiles is independently radiometric, sensor (sensor-related effects) and geometricallycorrected and aligned to a cartographic map projection (RapidEye, 2012). The resampled ground resolution of the orthorectified images is $5 \mathrm{~m}$. The study site is covered by two tiles, a northern and southern tile with an overlapping area of about $5.1 \mathrm{~km}^{2}$ (Fig. 2, IA 2). To obtain a better understanding of plant development, time-series images of periods longer than one year are desirable, in order to catch similar development stages twice. Since the temporal development of LAI plays a very significant role in the SVAT modelling process, time-series images are important for understanding the eventual seasonality of LAI (e.g. dry and rainy seasons). For this reason, our investigation was based on a time-series of 8 images obtained between 2011 and 2012 (Table 1).

The widely used ATCOR atmospheric correction algorithm assumes the presence of dense dark vegetation (DDV) in the image, which can be used as reference pixels with known surface reflection (Richter, 1996). The mask of reference pixels is computed using multiple thresholds of the vegetation index combined with red and near infrared (NIR) surface reflectance values. The first step of the atmospheric correction procedure is to determine the atmospheric turbidity for the reference pixels. Atmospheric turbidity is controlled by the meteorological range parameter ('visibility') in ATCOR. For atmospheric correction, ATCOR uses a database that stores compiled MODTRAN-4 atmospheric correction functions in look-up tables (Guanter, Richter, \& Kaufmann, 2009). Six standard atmospheric condition models and three aerosol types are assumed. One model for tropical regions is available (ERDAS \& Geosystems, 2011). The second step is to apply the determined atmospheric turbidity for the whole image. ATCOR allows us to select 


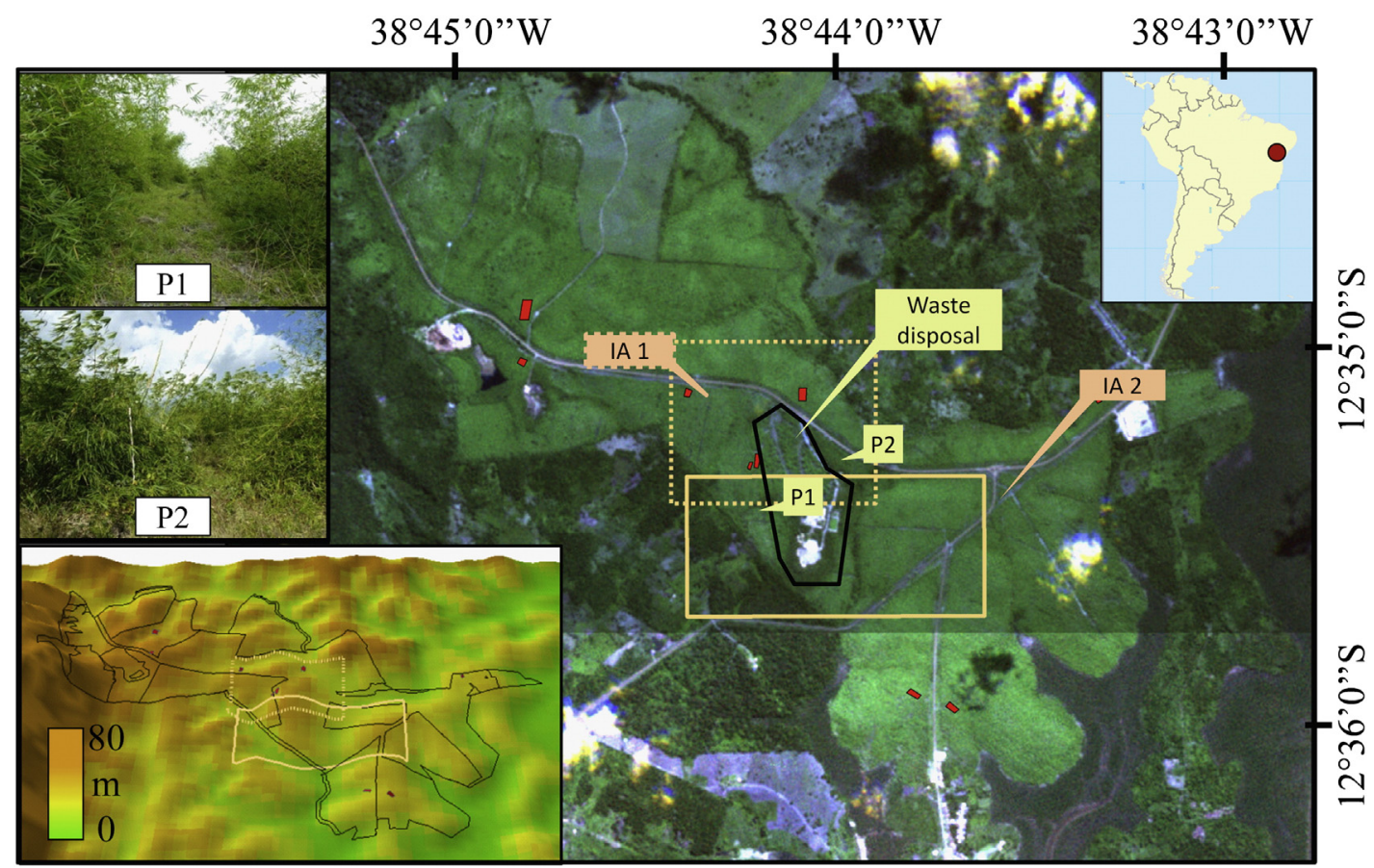

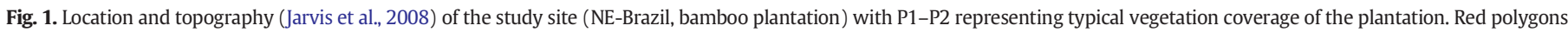

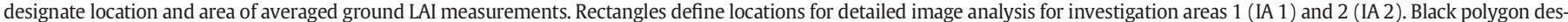

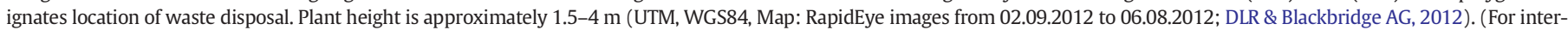
pretation of the references to colour in this figure legend, the reader is referred to the web version of this article.)

maritime, rural, urban and desert aerosol types for the correction. There are several more options for using ATCOR, which are controlled by setting appropriate parameters. Whereas ATCOR 2 is specifically designed for use over flat terrain, ATCOR 3 was developed for mountainous terrain and includes a terrain correction module. ATCOR 3 accounts for adjacency effects and considers bi-directional reflection properties. The correction procedures require several atmospheric and satellitedependent parameters, namely solar zenith angle, solar azimuth angle, sensor tilt angle, satellite azimuth angle and the land surface elevation (ERDAS \& Geosystems, 2011). A further description of the ATCOR algorithm is provided by Richter et al. (2006) and the user manual (ERDAS \& Geosystems, 2011). The best choice of parameters for atmospheric correction and subsequent LAI estimation is investigated in this paper. It is important to understand which ATCOR model parameters have the strongest influence on LAI retrieval, so that we know where to focus our efforts most during atmospheric correction.

\section{SVAT model description and sensitivity to LAI}

An example of a SVAT model is the coupled, process-based 1D 'CoupModel'. This model explicitly focuses on vegetation influence on the processes related to water, heat, carbon and nitrogen within the soil-plant-atmosphere continuum (Jansson \& Karlberg, 2010). CoupModel allows investigation and modelling at varying levels of complexity thanks to its modular structure and number of equations available for selection. The major model input requirements are climate
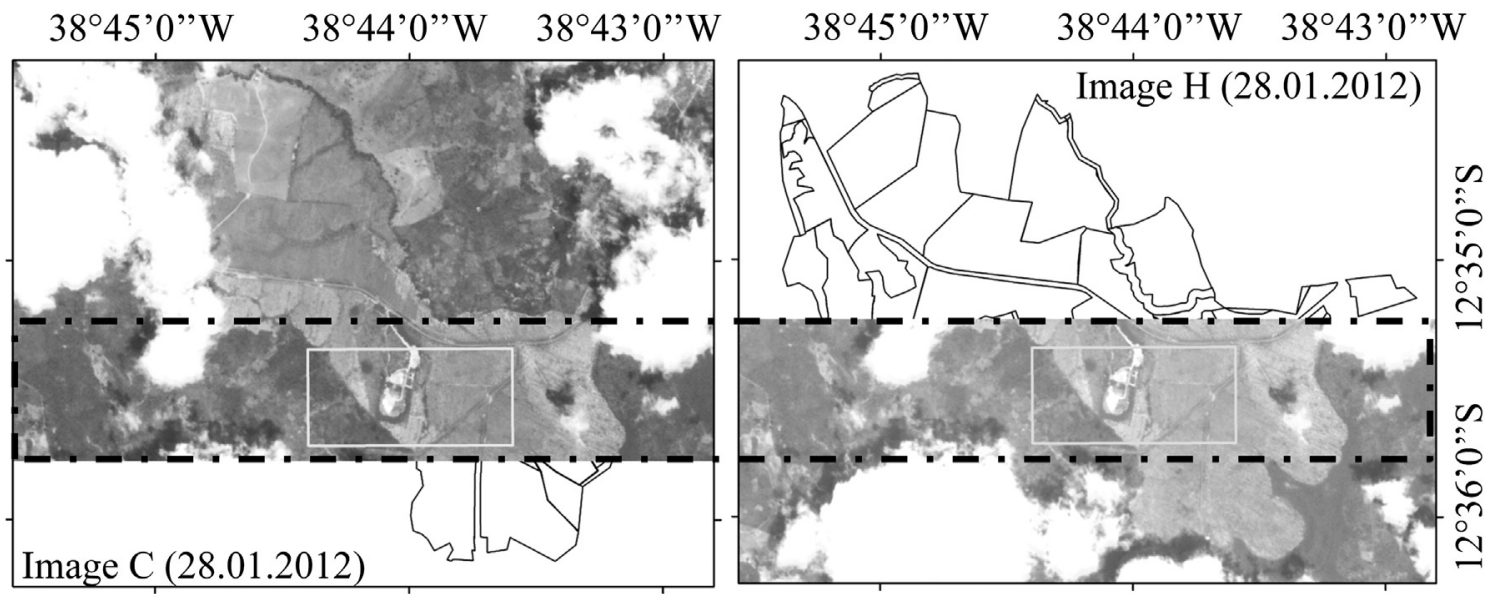

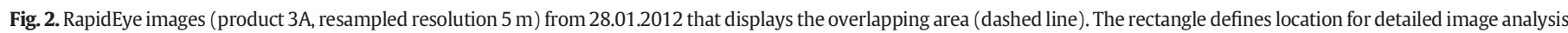
for overlapping consecutive images (Copyright DLR 2012). 
Table 1

RapidEye images used for atmospheric correction, VI determination and LAI estimation.

\begin{tabular}{lll}
\hline Designation & Image date & Tile location \\
\hline A & 04.08 .2011 & North \\
B & 05.12 .2011 & North \\
C $^{*}$ & 28.01 .2012 & North \\
D & 04.03 .2012 & North \\
E & 02.05 .2012 & North \\
$F^{\#}$ & 06.08 .2012 & North \\
$G^{\#}$ & 06.08 .2012 & South \\
$\mathrm{H}^{*}$ & 28.01 .2012 & South \\
I & 16.01 .2012 & North (not shown) \\
\hline
\end{tabular}

*\# designates image pairs for comparison.

data (e.g. precipitation), soil parameters (e.g. texture), and plant physiological parameters (e.g. LAI) (Jansson \& Karlberg, 2010). For additional detailed model description the reader is referred to Jansson and Karlberg (2010). The important equations for understanding model sensitivity to LAI changes are briefly described in the following section. The interception of water within the canopy is described in CoupModel as:

$\Delta \boldsymbol{S}=\boldsymbol{P}-\boldsymbol{E}-\boldsymbol{q}$,

where $\Delta \boldsymbol{S}$ is the change of intercepted water, $\boldsymbol{P}$ is the precipitation, $\boldsymbol{E}$ is the evaporation of intercepted water, and $\boldsymbol{q}$ is the through-fall. The interception capacity $\left(\boldsymbol{S}_{\max }\right)$ is directly related to LAI by the equation:

$\boldsymbol{S}_{\max }=\boldsymbol{i}_{\mathrm{LAI}} \times \mathrm{LAI} \times \boldsymbol{i}_{\mathrm{base}}$

where $\boldsymbol{i}_{\mathrm{LAI}}$ and $\boldsymbol{i}_{\text {base }}$ are plant characteristic parameters (Jansson \& Karlberg, 2010). All processes included in evapotranspiration are governed by the amount of energy put into the system as e.g. radiation. These energy processes are related to LAI light interception, which is explained by the Beer-Lambert law (Glenn et al., 2008) as follows:

$\boldsymbol{R}=\boldsymbol{R}_{\boldsymbol{n}} \times \boldsymbol{e}^{(-\boldsymbol{k} \times \mathrm{LAI})}$,

where $\boldsymbol{R}$ is the net radiation above canopy, $\boldsymbol{k}$ is an extinction coefficient, $\boldsymbol{R}_{\boldsymbol{n}}$ is the net radiation at soil surface and LAI is the leaf area index (Jansson \& Karlberg, 2010). Soil evaporation is then a function of net radiation at soil surface $\left(\boldsymbol{R}_{\boldsymbol{n}}\right)$, soil heat flux, aerodynamic resistance $\left(\boldsymbol{r}_{\boldsymbol{a d}}\right)$ from the soil to reference height above canopy, surface resistance at soil surface $\left(\boldsymbol{r}_{\boldsymbol{s}}\right)$, vapour pressure and some natural constants. The aerodynamic resistance $\left(\boldsymbol{r}_{\boldsymbol{a d}}\right)$ is directly related to LAI in the form of:

$\boldsymbol{r}_{\boldsymbol{a d}}=\boldsymbol{r}_{\boldsymbol{w t}}+(\boldsymbol{m} \times \mathrm{LAI})$

where $\boldsymbol{r}_{w t}$ is a function of wind speed and temperature, and $\boldsymbol{m}$ is an empirical coefficient (Jansson \& Karlberg, 2010). Transpiration is influenced by LAI through water uptake rate by roots, evaporation from the leaf surface, aerodynamic resistance or leaf water storage. The surface resistance is also used to calculate potential transpiration, which is then applied to estimate real transpiration (Jansson \& Karlberg, 2010).

\section{Methods}

The investigation methodology of atmospheric correction on LAI and SVAT models along with sources of associated uncertainties at each processing step are shown in Fig. 3.

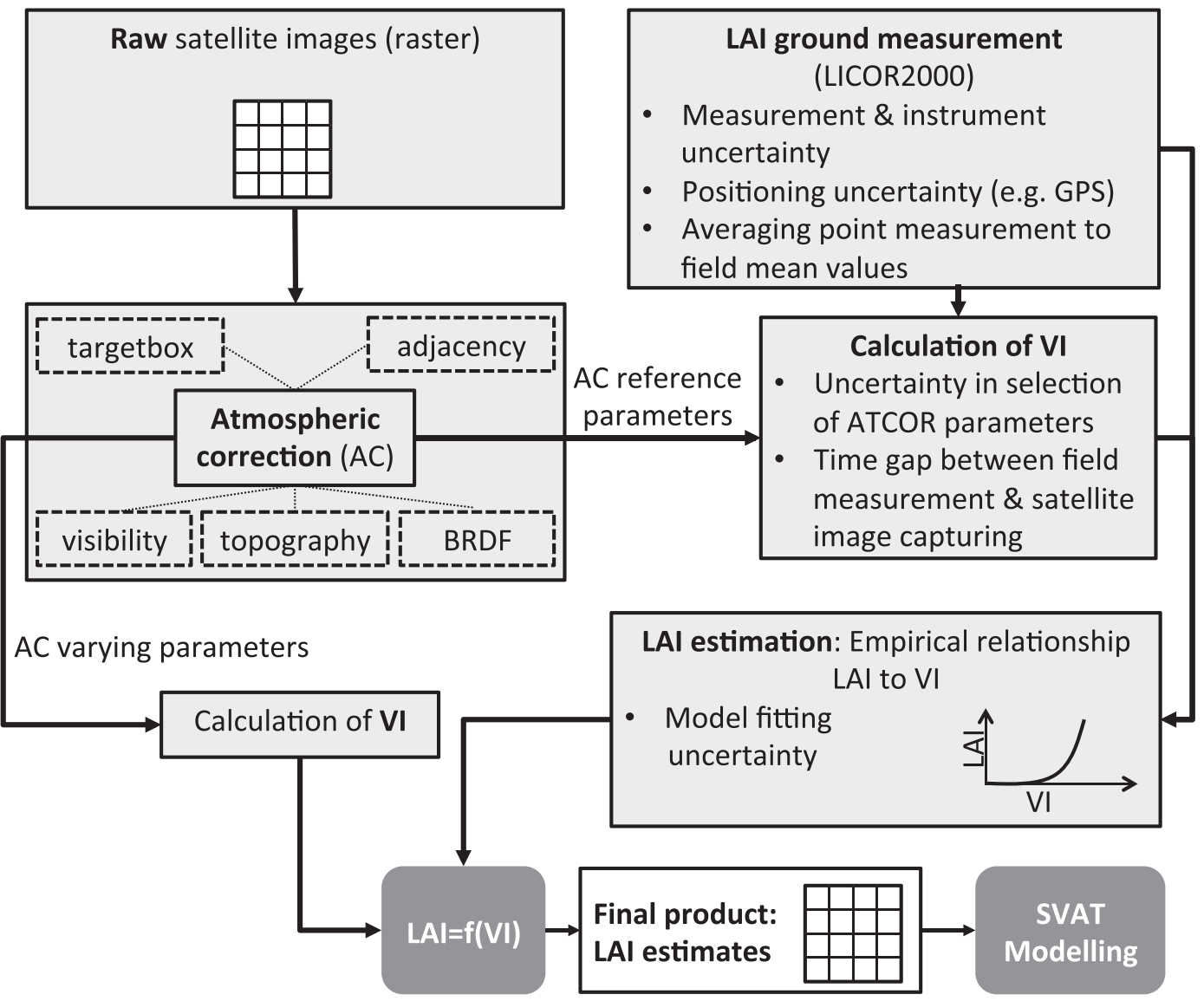

Fig. 3. Methodology of investigation approach and sources of uncertainty propagation. 


\subsection{Satellite image preparation}

Clouds were removed from all images based on cloud mask cover data provided together with delivered image package (DLR \& Blackbridge AG, 2012). The cloud mask cover was converted into a vector layer where clouds were then manually revised and adjusted using ArcMap10 software. The adjusted vector cloud mask was merged with the remote sensing image in order to exclude pixels that correspond to cloudy areas.

\subsection{Atmospheric correction with parameter variation}

Atmospheric correction was carried out using the ATCOR software in ERDAS IMAGINE 2010. In this current paper, the water vapour and ozone profiles of the tropical model atmosphere were used due to the classification as equatorial climate (Kottek et al., 2006). Total column absorber amounts are $4.1 \mathrm{~cm}$ precipitable water and 278 D.U. (water vapour and ozone content) in the tropical atmospheric model. Variations of ozone and water vapour content around the model values are negligible for the broad RapidEye spectral channels relative to variations of aerosol content (visibility). The aerosol type was fixed to maritime aerosols - due to the vicinity of the test site to the Atlantic Ocean coast (straight-line distance approx. $5 \mathrm{~km}$ (bay) to $50 \mathrm{~km}$ (ocean)). ATCOR parameters (e.g. satellite viewing angle) are extracted from the metafile of satellite images or are calculated using ATCOR. Topographic information was obtained from a digital elevation model (SRTMv4 DEM) with a spatial resolution of $90 \mathrm{~m}$ (Jarvis, Reuter, Nelson, \& Guevara, 2008). We first analyse the influence of 'visibility' variation on the blue, red, and NIR band of RapidEye images A to F. 'Visibility' was chosen since we assumed that this parameter has the strongest impact on reflectance values (ERDAS \& Geosystems, 2011). Hence, for each pixel of the investigation area 1 (IA 1, Fig. 1), we calculated the mean reflectance value along with standard deviation (SD) averaged over all atmospheric correction images for 'visibility' variation (16-40 km, Table 2$)$. The pixel mean values were then averaged over IA 1 as an indicator for the atmospheric correction influence.

The influence of single ATCOR parameter variations on LAI estimation was investigated via stepwise modification of single parameters, while at the same time keeping the other parameters constant. The analysis was carried out for 'visibility', 'target box' and 'adjacency range' with both ATCOR models (ATCORs 2 and 3). The step increments of our model parameters ('adjacency range', 'target box') were selected to be reasonable for our study site. We made sure that the parameters given as default settings by ATCOR for 'target box' ( 5 pixels) and 'adjacency' $(1000 \mathrm{~m})$ were included. The stepwise increment of the model parameter 'visibility' was selected so that the corresponding aerosol optical thickness increases approximately linearly. The non-linear relationship between visibility and aerosol optical thickness (AOT) was described by Richter and Schläpfer (2013) as:

$\mathrm{AOT}=e^{a(z)+b(z) \times \ln (\text { visibility })}$, where $z$ is the surface elevation (here $z=0$, sea level), $a(0)=1.54641$, and $b(0)=-0.854022$ (ERDAS \& Geosystems, 2011; Richter, personal communication, 2013). The topography and BRDF effect on LAI estimation was tested based on LAI comparison between ATCOR 2 and ATCOR 3 corrected images.

The evaluation of LAI estimation sensitivity is easier when the different LAI estimations caused by different atmospheric correction parameterisations are compared relative to a reference ATCOR parameterisation. The reference ATCOR parameterisation should be set up in a manner that leads to the most reasonable top of canopy (TOC) reflectance values, and thus LAI estimations for the studied area. The selected ATCOR parameterisations are summarised in Table 2.

Our definition of the reference parameters is based on spectral evaluation in the ATCOR module, where spectral characteristics of meadow and rainforest areas in each image were compared with the corresponding reference spectra provided by ATCOR. The model parameterisation, which best matches the reference spectra is used as the reference model parameterisation. As a reference 'visibility' value, around which we varied the visibility for our investigation, was set to $20 \mathrm{~km}$, whose selection was based on the spectral analysis in ATCOR. This value choice was supported by the corresponding horizontal visibility measured (12:00) for each image (exception image E, $18 \mathrm{~km}$ ) at the Salvador da Bahia airport (ICEA, 2013) and the value provided by World Meteorological Organization (WMO, 2013).

To analyse the effect of BRDF on LAI estimation, we calculated and applied a bi-directional reflectance distribution (BRDF) model using ATCOR 3 and based on reference model parameterisation (Table 2). BRDF models are generally useful for areas with low illumination (ERDAS \& Geosystems, 2011). The influence of topography on LAI estimation was investigated by comparing the LAI derivations from ATCOR 2 and ATCOR 3 for each image. Due to the relatively flat terrain of the study site, we expected to observe only low influence by topography and BRDF on LAI estimations. The resultant corrected images form the basis of further image processing, which is achieved by computation of VI and LAI estimation.

\subsection{Computation of vegetation indices}

As a prerequisite for LAI estimation, three different VI were calculated for each atmospherically corrected image for all atmospheric correction variants (Table 2). NDVI is calculated as:

$\mathrm{NDVI}=\frac{\mathrm{NIR}-\text { red }}{\mathrm{NIR}+\text { red }}$

where NIR is the reflectance in the near-infrared band and red is the red band (Huete, 1988; Rouse \& Haas, 1973).

SAVI is defined as:

$\mathrm{SAVI}=\frac{\mathrm{NIR}-\text { red }}{\mathrm{NIR}+\text { red }+L} \times(1+L)$,

where the adjustment factor $L$ is derived from a scatterplot of NIR and red band data (Huete, 1988). $L$ accounts for differences in light

Table 2

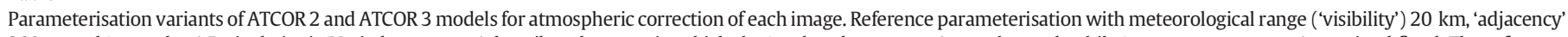

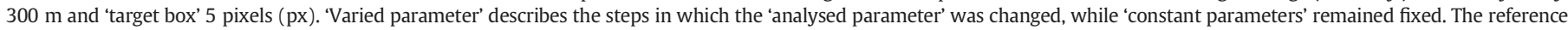
model parameters are designated by *.

\begin{tabular}{|c|c|c|c|c|c|c|}
\hline \multirow[b]{2}{*}{ Analysed parameter } & \multirow{2}{*}{$\begin{array}{l}\text { Varied parameter } \\
\text { Steps }\end{array}$} & \multicolumn{2}{|c|}{ Constant parameters } & \multirow[b]{2}{*}{ Target box/px } & \multicolumn{2}{|c|}{ Model } \\
\hline & & Adjacency/m & Visibility/km & & AT2 & AT3 \\
\hline Target box/px & $5^{*}, 10,15,20,40$ & 300 & 20 & / & $\mathrm{x}$ & $\mathrm{x}$ \\
\hline Adjacency $/ \mathrm{m}$ & $16,50,200,300^{*}, 500,1000,2000$ & / & 20 & 5 & $\mathrm{x}$ & $\mathrm{x}$ \\
\hline Topography (AT2 vs. AT3) & / & 300 & 20 & 5 & $\mathrm{x}$ & $\mathrm{x}$ \\
\hline BRDF & BRDF vs. No BRDF* & 300 & 20 & 5 & / & $\mathrm{x}$ \\
\hline Visibility/km & $16,17,18,20^{*}, 23,25,28,40$ & 300 & / & 5 & $\mathrm{x}$ & $\mathrm{x}$ \\
\hline
\end{tabular}


extinction by canopy in the red and NIR ranges. The information about different light extinctions is used to correct for background influences originated from soil (Huete, Liu, Batchily, \& van Leeuwen, 1997). SARVI includes the blue band in the calculation in order to reduce atmosphere influences. It is calculated as:

SARVI $=(1+P) \times \frac{\text { NIR }-(\text { red }-(\text { blue }- \text { red }))}{\text { NIR }+(\text { red }-(\text { blue }- \text { red }))+P}$,

where blue is the reflectance in the blue band and $P$ is similar to $L$, in that it is an adjustment factor to account for soil influences (Kaufman \& Tanré, 1992) but has different values due to the interaction between the soil adjustment factor and aerosol resistance term (Liu \& Huete, 1995).

\subsubsection{Investigation of two successive images}

In order to verify the LAI differences that still exist after applying the same atmospheric correction parameterisation on two different successive images (obtained from same date), the estimated LAI values of both images are compared. These differences occur because the atmospheric correction of both images relies on independent, different dense dark vegetation (DDV) pixels. We analysed the LAI uncertainty for two image pairs (images $C$ and $H$ from 28.01.2012, and images F and G from 06.08.2012) and found that when combined, they completely cover the entire study site and have an overlapping area (Fig. 2, IA 2). The image pairs with an overlapping area were atmospherically processed using ATCOR 3 model with reference parameterisation (Table 2). The image pairs were visually investigated and manually co-registered using $\mathrm{R}$, to assure that the corresponding pixels of each image matched. The LAI estimation of pixel values from these overlapping areas for both corrected images of one image pair (C, $\mathrm{H}$ and $\mathrm{F}, \mathrm{G}$ ) were compared.

\subsection{LAI field measurement}

Field LAI was measured at the study site during the period 24th February to 4th March 2012 (image D) for 9 different bamboo development stages with the LICOR-LAI2000 instrument (Fig. 1). In order to derive a LAI mean value for a specific bamboo development stage, 15 LAI LICOR single measurements per bamboo field were averaged to an area mean LAI $(\approx 25 \times 25 \mathrm{~m})$. One LAI LICOR single measurement consists of two 'above canopy' and five 'below canopy' measurements.

\subsection{Establishment of empirical LAI retrieval model}

For LAI estimation from satellite images, an empirical relationship between bamboo field-specific LAI measured and the corresponding VI was computed. The VI calculation was carried out based on our reference atmospheric correction results (Section 5.2) from RapidEye images. In order to derive a mean VI value for each bamboo field, we averaged the VI values that cover the corresponding LAI ground-measurement area (Fig. 1). An exponential function with LAI $=\left(\boldsymbol{a} \times \boldsymbol{e}^{(\boldsymbol{b} \times \mathrm{VI})}\right)$ was fitted to the averaged ground-measured LAI of each bamboo field and mean VI values (Fig. 5) were obtained using non-linear least-squares regression in $\mathrm{R}$ (package 'stats'). An additional fitting point corresponding to bare soil $((\mathrm{LAI}, \mathrm{VI})=(\approx 0, \approx 0))$ was used in our regression, which was derived by analysing VI at the image location of bare soil, where LAI is assumed to be close to zero. The resultant regression functions are (Eqs. 9 to 11$)$ :

$\mathrm{LAI}=0.061 \times \boldsymbol{e}^{4.563 \times \mathrm{NDVI}}$, with $\mathrm{R}_{\text {Spearman }}^{2}=0.97$

$\mathrm{LAI}=0.167 \times \boldsymbol{e}^{3.564 \times \mathrm{SAVI}}$, with $\mathrm{R}_{\text {Spearman }}^{2}=0.97$

$\mathrm{LAI}=0.426 \times \boldsymbol{e}^{3.163 \times \mathrm{SARVI}}$, with $\mathrm{R}_{\text {Spearman }}^{2}=0.89$
Six LAI ground averages could be correlated in this way to match VI. Unfortunately, two of the ground-truth LAI sampling locations were covered by clouds on 4th March 2012 and could not be used for regression of VI and LAI. To provide a broader basis for the regression, SARVI values corresponding to two additional development stages from two further images obtained on 16.01.2012 (I) and 28.01.2012 (H) were included in our regression between SARVI and ground-measured LAI. The inclusion of SARVI values is possible, since we assume that SARVI is less sensitive to atmospheric influences than NDVI and SAVI. The supplementary SARVI values were permissible since they correspond to bamboo development stages where the plants are already well developed (Embaye, Weih, Ledin, \& Christersson, 2005). Therefore, we have assumed that the LAI increase from January (16.01.2012 and 28.01.2012) to March (04.03.2012) is negligible, and that the LAI values are therefore comparable.

For the derivation of SAVI, Huete (1988) recommends an adjustment factor $L$ in Eq. 7, ranging from 0 (dense vegetation) to $\approx 1$ (low vegetation). A value of 0.5 represents intermediate dense vegetation. We found the best empirical correlation between ground measured LAI and SAVI for $L=0.1$. This low $L$ factor is required because of the relatively high LAI of bamboo plants. Even in areas with wider spacing between bamboo rows, the bare soil is generally covered by dense bamboo litter that mitigates soil reflectance or scattering. In contrast, the $P$ coefficient used in SARVI calculation was extracted as being the slope of the soil-line. The soil-line is formed by the linear relationship of bare soil reflectance in the scatterplot of NIR vs. red band values (Baret, Jacquemoud, \& Hanocq, 1993; Richardson \& Wiegand, 1977). The $P$ coefficient used in SARVI calculation (Eq. 8) was found to be approx. $P=1.1$ for all analysed images. The $P$ coefficient as the slope of the soil line is much higher than the $L$ factor in SAVI, because the soil line was calculated from a NIR versus red plot for the whole investigation area 2 (Fig. 1), including open bare soil areas (e.g. waste disposal). Additionally, the soil colour is yellowish and reddish due to high iron-oxide content. This increases the disturbing influence upon the soil and means that a high $P$ value is required (Huete, 1988).

\subsection{Sensitivity of SVAT model to LAI}

In order to determine the importance of LAI precision on SVATmodel output components, a simple local CoupModel sensitivity analysis to LAI changes (with LAI as an input parameter) was carried out. This study exclusively investigates the model sensitivity to LAI based on interception and evapotranspiration, as well as separate process evaporation and transpiration. This is important, since leaf area either directly or indirectly influences the corresponding processes, which is represented as LAI in the related equations used in the SVAT model (Eqs. 1 to 4 ).

In our sensitivity analysis with CoupModel, vegetation is considered as an explicit single big leaf, where evapotranspiration is calculated using the Penman-Monteith-Equation and a simple soil surface resistance equation (Jansson \& Karlberg, 2010; Monteith, 1965). Soil hydraulic properties are estimated using the van-Genuchten-Mualem approach (Ghanbarian-Alavijeh, Liaghat, Huang, \& Van Genuchten, 2010; Jansson \& Karlberg, 2010). CoupModel was set up with daily climate data from 2011 obtained from a nearby climate station, as described in Mannschatz and Dietrich (2013). A soil profile was parameterised based on four representative soil-sampling locations. The corresponding soil texture and organic content was obtained from laboratory analysis of soil samples, from depths of 0-10 cm, 10-30 cm, 30-70 cm and 70$100 \mathrm{~cm}$, which were collected at the study site in the years 2011 and 2012. Soil hydraulic characteristics where estimated by pedo-transfer functions from soil texture using CoupModel. Vegetation type was parameterised as bamboo (B. vulgaris), mainly using relevant literature information and our own field observation. LAI is increased at each run from 0.01 to 10 in 0.5 steps and the related model output is recorded. The model outputs from different runs are compared relative to a reference SVAT model parameterisation, with a $\mathrm{LAI}(\mathrm{LAI}=3.2)$ value that is 
typical for the study site. Model sensitivity is further evaluated based on a normalised sensitivity index (SI) that describes the relative model output to the relative model parameter change (Lenhart, Eckhardt, Fohrer, \& Frede, 2002). The SI indicates the relationship between input parameter change and model output change. This value is e.g. positive if an increase of the input parameter results in an increase of output parameter. Model sensitivity is divided into four classes small $(|\mathrm{SI}|<0.05)$, medium $(|\mathrm{SI}|=0.05$ to 0.20$)$, high $(|\mathrm{SI}|=0.20$ to 1.00 ), and very high ( $|\mathrm{SI}|>1.00$ ) (Lenhart et al., 2002). The sensitivity index (SI) is calculated as

$\mathrm{SI}=\frac{\left(\boldsymbol{y}_{2}-\boldsymbol{y}_{1}\right) / \boldsymbol{y}_{0}}{2 \times\left(\boldsymbol{x}_{2}-\boldsymbol{x}_{1}\right) / \boldsymbol{x}_{0}}$,

where $\boldsymbol{y}_{0}$ is the model output computed at initial input parameterisation $\boldsymbol{x}_{0}$ (here LAI $=3.2$ ). The initial value $\left(\boldsymbol{x}_{0}\right)$ is varied by $\pm \Delta \boldsymbol{x}$ (with $\left.\boldsymbol{x}_{1}=\boldsymbol{x}_{0}-\Delta \boldsymbol{x} ; \boldsymbol{x}_{2}=\boldsymbol{x}_{0}+\Delta \boldsymbol{x}\right)$, resulting in the corresponding model output values $\boldsymbol{y}_{1}, \boldsymbol{y}_{2}$ (Lenhart et al., 2002).

\section{Results and discussion}

The following section presents the results of reflectance, VI and LAI variability due to atmospheric correction for images A to F, as well as the LAI difference between the overlapping areas of images $\mathrm{C}$ and $\mathrm{F}$ (north) and $\mathrm{H}$ and $\mathrm{G}$ (south). The sources of error propagation are summarised in Fig. 3. However, in this study we focused on the remote sensing image processing, but remained aware of the fact that there are some sources of general uncertainty associated with field LAI measurements, as well as its relationship to VI.

\subsection{Influence of atmospheric correction on RapidEye bands}

The variability of band reflectance, as well as the VI of each pixel induced by changing 'visibility' (16-40 km), is given in Fig. 4 as a mean value over the investigation area 1 (IA 1, Fig. 1) averaged over images $\mathrm{A}$ to $\mathrm{F}$. The mean relative error averaged over all images $\mathrm{A}$ to $\mathrm{F}$ is highest for the blue band (ATCOR $2=26.9 \%$, ATCOR $3=31.7 \%$ ), followed by the red $($ ATCOR $2=9.0 \%$, ATCOR $3=9.5 \%$ ), and NIR band $($ ATCOR $2=1.7 \%$, ATCOR $3=1.8 \%$ ). An increase in relative error was expected in the case where reflectance decreases (Miura, Heute, Yoshioka, \& Holben, 2001). For this reason, large relative errors occurred due to the generally low mean reflectance in red and NIR bands $(<10 \%)$. However, this is the information that is important for vegetated areas that commonly have high NIR reflectance (ERDAS \& Geosystems, 2011). Additionally, uncertainty in the blue band (SD) is highest, since this band has the greatest atmospheric influences exerted upon it and is therefore subject to the strongest level of correction by the ATCOR algorithm. In general, relative error of mean reflectance values are slightly greater for ATCOR 3 compared to ATCOR 2.

The uncertainty of reflectance values in the blue, red and NIR bands, caused by visibility variation during atmospheric correction, seems to be buffered by the computation of VI (Fig. 4). The mean relative error of ATCOR 2-3 is similar for NDVI (2.7-2.8\%), SAVI (2.6-2.8\%) and SARVI (2.8-2.9\%) (Fig. 4). The mean SD of reflectance values for studied images A to F of IA 1 is in the order of $0.01 \%$ (SARVI) to $0.02 \%$ (NDVI, SAVI), which is in a similar range to the values reported by (Miura et al., 2001) (Fig. 4). As expected, the SD of non-atmospheric resistant VIs (NDVI, SAVI) increases with an increase of absolute VI values, which becomes visible from plotting calculated SD values of each pixel (not shown) (Miura et al., 2001). However, the average SD values of

\begin{tabular}{|c|c|c|c|c|c|c|c|c|c|}
\hline \multirow[t]{2}{*}{ Parameter } & \multirow{2}{*}{\multicolumn{2}{|c|}{$\begin{array}{l}\text { TOC Reflectance } \backslash \% \\
\text { (mean SD (rE } \backslash \% \text { ) of } \\
\text { images A to F) }\end{array}$}} & \multirow{2}{*}{\multicolumn{2}{|c|}{$\begin{array}{c}\text { VI } \\
\text { (mean } \mathrm{SD}(\mathrm{rE} \backslash \%) \text { of } \mathrm{A} \\
\text { to } \mathrm{F})\end{array}$}} & \multirow{2}{*}{\multicolumn{2}{|c|}{$\begin{array}{c}\mathbf{L A I}_{\mathbf{V I}} \\
\text { (mean } \mathrm{SD}(\mathrm{rE} \backslash \%) \text { of } \mathrm{A} \\
\text { to } \mathrm{F})\end{array}$}} & \multicolumn{3}{|c|}{$\begin{array}{c}\text { SVAT model component } \\
\text { change } \backslash \% \\
(\text { for }+/- \text { SD LAI } \\
\text { VI }\end{array}$} \\
\hline & & & & & & & & + LAI & -LAI \\
\hline \multirow{12}{*}{$\begin{array}{l}\text { Visibility } \\
(16-40 \mathrm{~km})\end{array}$} & \multirow{4}{*}{ Blue } & AT2: 0.64 (26.9) & \multirow{4}{*}{ NDVI } & \multirow{2}{*}{ AT2: 0.02 (2.7) } & \multirow{4}{*}{$\mathrm{LAI}_{\mathrm{NDVI}}$} & \multirow{2}{*}{ AT2: 0.24 (10.2) } & I & +6.6 & -6.5 \\
\hline & & & & & & & E & -7.8 & +9.1 \\
\hline & & \multirow{2}{*}{ AT3: $0.69(31.7)$} & & \multirow{2}{*}{ AT3: 0.02 (2.8) } & & \multirow{2}{*}{ AT3: 0.26 (10.7) } & $\mathrm{T}$ & +3.1 & -0.7 \\
\hline & & & & & & & ET & -1.7 & +2.8 \\
\hline & \multirow{4}{*}{ Red } & \multirow{2}{*}{ AT2: 0.49 (9.0) } & \multirow{4}{*}{ SAVI } & \multirow[t]{2}{*}{ AT2: 0.02 (2.6) } & \multirow{4}{*}{$\mathrm{LAI}_{\mathrm{SAVI}}$} & \multirow{2}{*}{ AT2: 0.15 (7.0) } & $-\mathrm{I}$ & +3.9 & -4.0 \\
\hline & & & & & & & $\mathrm{E}$ & -4.8 & +5.4 \\
\hline & & \multirow{2}{*}{ AT3: $0.51(\mathbf{9 . 5})$} & & \multirow{2}{*}{ AT3: $0.02(\mathbf{2 . 8})$} & & \multirow{2}{*}{ AT3: $0.16(7.2)$} & $\mathrm{T}$ & +1.9 & -0.5 \\
\hline & & & & & & & ET & -1.1 & +1.6 \\
\hline & \multirow{4}{*}{ NIR } & \multirow{2}{*}{ AT2: 0.78 (1.7) } & \multirow{4}{*}{ SARVI } & \multirow{2}{*}{ AT2: 0.01 (2.8) } & \multirow{4}{*}{$\mathrm{LAI}_{\mathrm{SARVI}}$} & \multirow{2}{*}{ AT2: 0.10 (4.5) } & $-I$ & +2.2 & -2.2 \\
\hline & & & & & & & $\mathrm{E}$ & -2.9 & +3.0 \\
\hline & & \multirow{2}{*}{ AT3: 0.83 (1.8) } & & \multirow{2}{*}{ AT3: $0.01(\mathbf{2 . 9})$} & & \multirow{2}{*}{ AT3: 0.09 (4.6) } & $\mathrm{T}$ & +1.0 & -0.5 \\
\hline & & & & & & & ET & -0.7 & +0.9 \\
\hline \multirow{2}{*}{$\begin{array}{l}\text { Adjacency } \\
(16-2000 \mathrm{~m})\end{array}$} & & & & & \multicolumn{2}{|c|}{ LAI $_{\text {SARVI }}$ AT2: 0.11 (5.3) } & ET & -0.9 & +1.1 \\
\hline & & & & & $\mathrm{LAI}_{\mathrm{S} A}$ & ARVI AT3: $0.02(\mathbf{0 . 8 )}$ & ET & -0.2 & +0.2 \\
\hline Target box & & & & & $\mathrm{LAI}_{\mathrm{S}}$ & ARVI AT2: 0.01 (0.4) & ET & -0.1 & +0.1 \\
\hline$(5-40 \mathrm{px})$ & & & & & $\mathrm{LAI}_{\mathrm{S}}$ & ARVI AT3: 0.03 (1.3) & ET & -0.2 & +0.3 \\
\hline $\begin{array}{l}\text { BRDF } \\
\text { (yes vs. No) }\end{array}$ & & & & & & $\mathrm{AI}_{\mathrm{SARVI}}: 0.10(\mathbf{5 . 3 )}$ & ET & -0.8 & +1.0 \\
\hline $\begin{array}{l}\text { Topography } \\
\text { (AT2 vs. AT3) }\end{array}$ & & & & & & LAI $_{\text {SARVI }}: 0.09(/)$ & ET & -0.7 & +0.9 \\
\hline
\end{tabular}

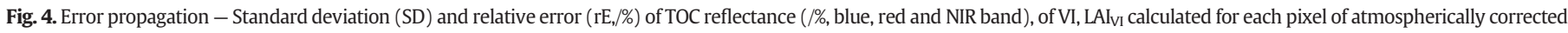

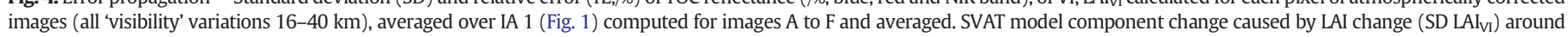
reference LAI (3.2) for interception (I), evaporation (E), transpiration (T) and evapotranspiration (ET). Grey shaded fields correspond to ATCOR 3 results. 
VI presented in Fig. 4 do not conclusively show this relationship. Nevertheless, the magnitude of absolute mean values is quite different for each VI, being smallest for SARVI and highest for NDVI.

\subsection{Uncertainty of LAI field measurements and empirical relationship}

The field estimation of LAI with LICOR LAI-2000 is assumed to underestimate direct LAI measurements. The reported underestimation varies depending on vegetation type and is generally about 20-50\% (Bréda, 2003), $15.2 \%$ for a beech forest (Bréda, 2003) and 26.5\% for a deciduous forest (Cutini, Matteucci, \& Mugnozza, 1998). Additional uncertainty associated with the calculation of mean LAI for each of the sampled bamboo fields is caused by vegetation heterogeneity (e.g. open areas). Nevertheless, the uncertainty caused by heterogeneity is expected to be small, because plants are planted in rows at the plantation. The fitting uncertainty of field LAI measurement to VI based on Eqs. 9-11 is given in Fig. 5. The different magnitudes of VI (Section 6.1) lead to different empirical relationships and to different LAI estimates.

\subsection{Influence of ATCOR parameterisation on LAI estimation}

The sensitivity of LAI estimation to ATCOR parameterisation is an evaluation based on the sensitivity index (SI) and is calculated (Eq. 12$)$ relative to the reference parameterisation $\left(\boldsymbol{x}_{0}, \boldsymbol{y}_{0}\right)$, with $\boldsymbol{x}_{1}$ and $\boldsymbol{x}_{2}$ being the maximum and minimum variation ranges of the ATCOR parameters. SI is calculated as a mean value for images A to $F$.

\subsubsection{Influence of topography}

The mean absolute LAI difference \pm SD for images $\mathrm{A}$ to $\mathrm{F}$ is $0.07 \pm$ 0.05 for $\mathrm{LAI}_{\mathrm{NDVI}}, 0.05 \pm 0.03$ for $\mathrm{LAI}_{\mathrm{SAVI}}$, and $0.13 \pm 0.09$ for $\mathrm{LAI}_{\mathrm{SARVI}}$ (Tables 3 and 4). The sensitivity index based on images $A$ to $F$ is small for $\operatorname{LAI}_{\mathrm{NDVI}}(\mathrm{SI}=-0.01)$, $\mathrm{LAI}_{\mathrm{SAVI}}(\mathrm{SI}=0.00)$, and $\mathrm{LAI}_{\mathrm{SARVI}}(\mathrm{SI}=0.04)$, confirming the observed similarity. The sensitivity of LAI estimates to the use of topography in the atmospheric correction is shown in Fig. 7. We conclude that the selection of ATCOR model type (ATCOR 2 or ATCOR 3) does not seem to influence the magnitude of LAI uncertainty caused by atmospheric correction at our study site for $\mathrm{LAI}_{\mathrm{NDVI}}$ and $\mathrm{LAI}_{\mathrm{SAVI}}$ (Tables 3 and 4). The negligible terrain effect was expected, due to the flat topography of the study site. The effect of topography is similar to the effect of visibility changes for LAI $_{\text {SARVI }}$ estimation.

\subsubsection{Influence of BRDF effects}

The sensitivity index for BRDF effects on LAI estimates is small for $\operatorname{LAI}_{\text {NDVI }}(\mathrm{SI}=0.01)$ and $\mathrm{LAI}_{\mathrm{SAVI}}(\mathrm{SI}=0.04)$, and medium for $\mathrm{LAI}_{\mathrm{SARVI}}$ $(\mathrm{SI}=0.07)$. Together with the SI result for topography, $\mathrm{LAI}_{\mathrm{SARVI}}$ is slightly more sensitive to terrain influences than $\mathrm{LAI}_{\mathrm{NDVI}}$ and $\mathrm{LAI}_{\mathrm{SAVI}}$. Similarly to topography influences, the mean absolute LAI difference \pm SD for BRDF effect is small, being $0.03 \pm 0.02$ for $\mathrm{LAI}_{\mathrm{NDVI}}, 0.09 \pm 0.07$ for $\mathrm{LAI}_{\mathrm{SAVI}}$,

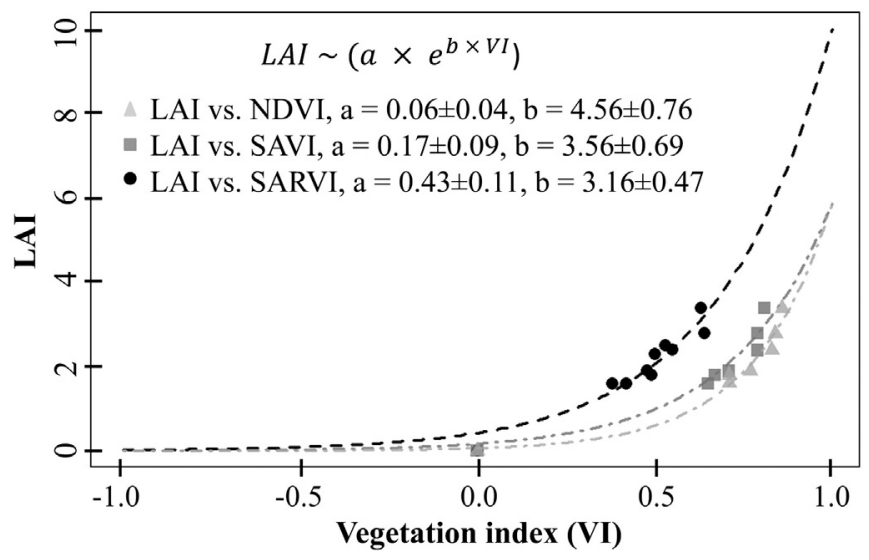

Fig. 5. Empirical relationship between ground-measured LAI and VI (NDVI, SAVI, SARVI). and $0.14 \pm 0.10$ for $\mathrm{LAI}_{\text {SARVI }}$ (Tables 3 and 4 ). Considering the maximal absolute differences, it becomes clear that, for some of the satellite images, the BRDF correction is important. The main reason for this is due to different illumination geometry, which depends on the configuration of the sun's position and satellite viewing angles. In case of an unfavourable satellite-sun-configuration (large zenith angles and large relative sun-satellite azimuth angles, where satellite viewing and illumination direction is the same), it is recommended to apply a BRDF correction on the satellite image, even for flat terrain where smaller BRDF effects are expected. Since our satellite viewing and sun zenith angles are relatively small $\left(<35^{\circ}\right)$, the expected BRDF effects are low. However, at the investigation area, zenith angles are larger in August than in February, thereby leading to higher BRDF effects in August, which contribute to higher maximal absolute LAI differences between images with and without BRDF correction. The influence of illumination geometry on LAI estimation is particularly strong at sites with dense vegetation (caused by canopy surface) due to the constellation of satellite viewing and illumination angle. For this reason, the highest maximal absolute LAI differences occur in the images $\mathrm{A}, \mathrm{E}$ and $\mathrm{F}$, where well-developed bamboo vegetation is present. In images $\mathrm{E}$ and $\mathrm{F}$, the bamboo vegetation is shown regrown again after the harvest, which can be seen in image B (Fig. 6, Tables 3 and 4). LAI maximal absolute differences are related to $\mathrm{VI}$, with $\mathrm{LAI}_{\mathrm{NDVI}}=1.40, \mathrm{LAI}_{\mathrm{SAVI}}=$ $0.56, \mathrm{LAI}_{\mathrm{SARVI}}=0.89$ for image $\mathrm{A} ; \mathrm{LAI}_{\mathrm{NDVI}}=0.45, \mathrm{LAI}_{\mathrm{SAVI}}=0.31$, $\mathrm{LAI}_{\mathrm{SARVI}}=0.60$ for image $\mathrm{E}$; and $\mathrm{LAI}_{\mathrm{NDVI}}=0.06, \mathrm{LAI}_{\mathrm{SAVI}}=0.43$, $\mathrm{LAI}_{\text {SARVI }}=1.05$ for image $\mathrm{F}$ (Tables 3 and 4$)$.

\subsubsection{Influence of ATCOR parameters}

The sensitivity index was calculated based on 'visibility' variation between $\boldsymbol{x}_{1}=16 \mathrm{~km}$ to $\boldsymbol{x}_{2}=40 \mathrm{~km}$ and the reference 'visibility' $\boldsymbol{x}_{0}=$ $20 \mathrm{~km}$. This range corresponds to variation of aerosol optical thickness at $550 \mathrm{~nm}$ between 0.20 and 0.44 and covers the majority of atmospheric turbidity that is found in nature. The sensitivity index for meteorological range ('visibility') effects on LAI estimation using ATCOR $2 / 3$ is medium for $\mathrm{LAI}_{\mathrm{NDVI}}(\mathrm{SI}=0.10 / \mathrm{SI}=0.11)$, as well as for $\mathrm{LAI}_{\mathrm{SAVI}}(\mathrm{SI}=0.07 / \mathrm{SI}=$ $0.08)$, and small for $\mathrm{LAI}_{\mathrm{SARVI}}(\mathrm{SI}=0.05 / \mathrm{SI}=0.05)$. The LAI uncertainty (mean LAI \pm SD of images A to F) derived from ATCOR $2 / 3$ atmospheric correction with varying 'visibility' is $2.3 \pm 0.24 / 2.4 \pm 0.26$ for $\mathrm{LAI}_{\mathrm{NDVI}}$, $2.2 \pm 0.15 / 2.3 \pm 0.16$ for $\mathrm{LAI}_{\mathrm{SAVI}}$, and $2.1 \pm 0.10 / 2.0 \pm 0.09$ for $\mathrm{LAI}_{\mathrm{SARVI}}$. Looking at the mean LAI of investigation area 1 , the ATCOR model type does not seem to exert influence upon the magnitude of LAI uncertainty. Furthermore, the LAI frequency distribution for the maximum and minimum parameterisation values for 'visibility' reveals a very similar pattern for ATCORs 2 and 3 (figure not shown). A low meteorological range tends to produce a higher frequency of high LAI estimations than high meteorological range values (Fig. 7). The differences that arise for mean LAI estimations of IA 1 between ATCORs 2 and 3 dependent on 'visibility' show a small offset for $\mathrm{LAI}_{\mathrm{NDVI}}$ and $\mathrm{LAI}_{\mathrm{SAVI}}$, which decreases with visibility increase. A large offset shows the $\mathrm{LAI}_{\mathrm{SARV}}$, being less dependent from visibility than $\mathrm{LAI}_{\mathrm{SAVI}}$ and $\mathrm{LAI}_{\mathrm{NDVI}}$ (Fig. 7). This reflects the relationship between increase of topography sensitivity of NDVI and SAVI with decreasing visibility (Fig. 7). In contrast, SARVI seem to be insensitive to topography from visibility changes based on its relatively constant offset. However, based on SD Tables 3 and 4 reveal that the absolute LAI estimation sensitivity to topography increases gradually from SAVI, NDVI to SARVI at reference atmospheric correction ('visibility' $=20 \mathrm{~km}$ ).

The SI for 'adjacency range' effects and 'target box' is negligible, with $\mathrm{SI}=0.00$ for all $\mathrm{LAI}_{\mathrm{VI}}$. Whereas there is no relevant difference between the sensitivity and generated SD of LAI estimates from ATCORs 2 and 3 for the model parameter 'visibility', the parameters 'adjacency range' and 'target box' show slightly different sensitivities for the various ATCOR model types.

LAI variability of model parameterisation between the 'adjacency range' $16 \mathrm{~m}$ and $2000 \mathrm{~m}$ is higher for ATCOR 2 (e.g. LAI $\mathrm{NDVI}_{\mathrm{N}}$ mean $\mathrm{SD}=0.13)$ compared to ATCOR $3\left(\mathrm{LAI}_{\mathrm{NDVI}}\right.$ mean $\left.\mathrm{SD}=0.03\right)$ 
Table 3

Mean and standard deviation (SD) of $\mathrm{LAI}_{\mathrm{SARVI}}, \mathrm{LAI}_{\mathrm{NDVI}}$ and $\mathrm{LAI}_{\mathrm{SAVI}}$ for each detailed investigation area (Fig. 1) for images A to $\mathrm{F}$ and for all applied atmospheric correction schemes.

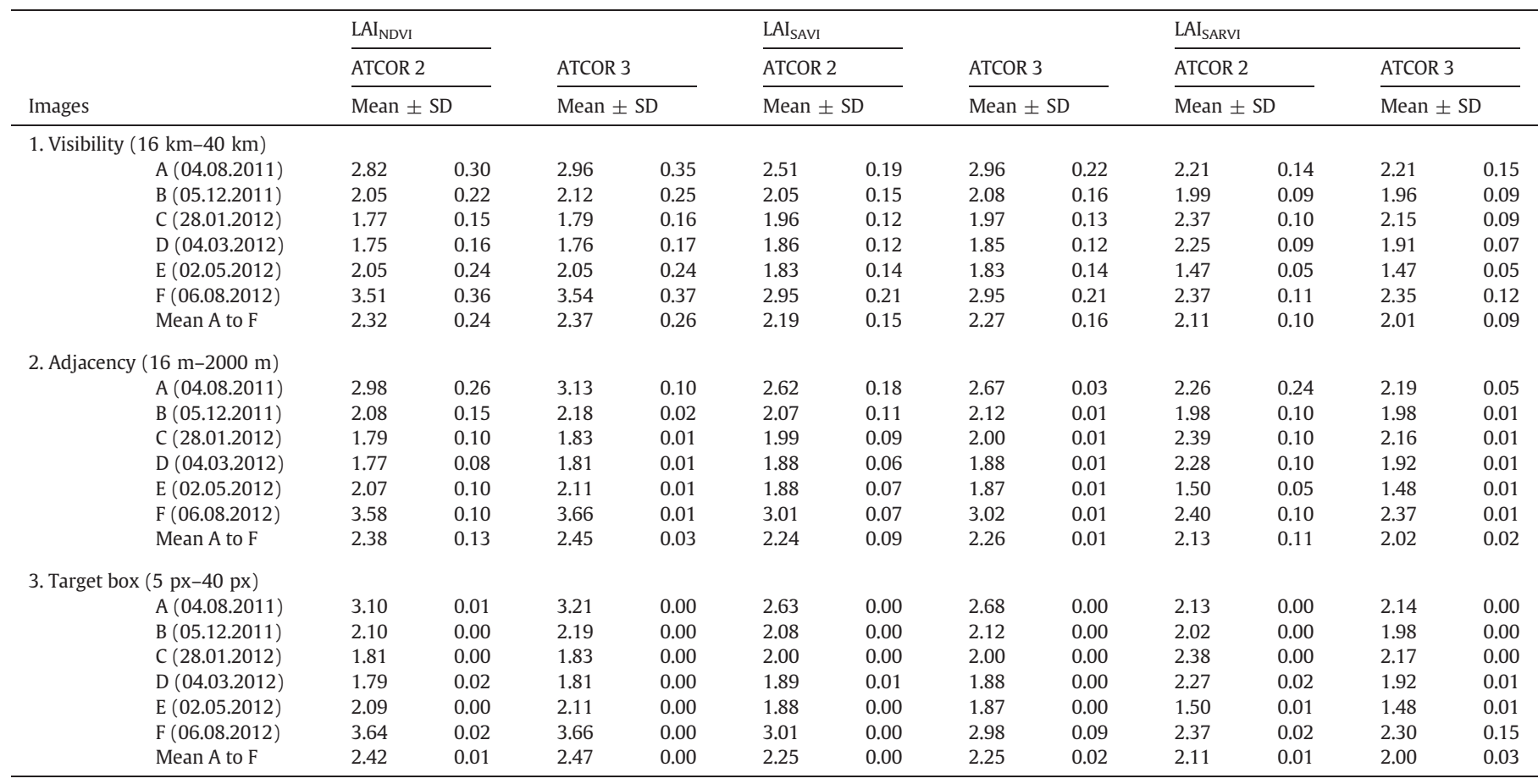

(Tables 3 and 4). Conclusively, ATCOR 3 provides a more robust LAI estimation for adjacency effects compared to ATCOR 2.

In the case of the 'target box' parameter, the LAI uncertainty (SD) caused by ATCOR 3 (e.g. LAI SAVI $_{\text {mean }} \mathrm{SD}=0.02$ ) is marginally higher

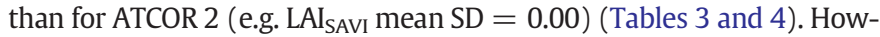
ever, these differences are, as the sensitivity index has already indicated, negligible. Based on SI, the sensitivity of LAI estimation to ATCOR parameterisation can be ordered in ascending sensitivity as follows: 'adjacency range', 'target box' < 'topography', BRDF < 'visibility'. Applying the ATCOR 3 model, LAI $_{\text {SARVI }}$ is an exception to that order, because the effect of topography, visibility and BRDF are similar. When comparing the LAI uncertainty based on SD, we can see that ATCOR 2 is influenced first of all by changes in 'visibility' and secondly by 'adjacency'. In contrast, ATCOR 3 produces more robust LAI estimations and meaningful influence is solely exerted by 'visibility' changes (Tables 3 and 4). The order of the influencing parameters corresponds to a large extent to our expectations, taking the characteristics of the study site into consideration. The flat terrain leads to small differences in our results for ATCORs 2 and 3 ('topography') (Fig. 1). The relatively low BRDF impact on LAI estimation was surprising (exception LAI $_{\text {SARVI }}$ where BRDF effect is similar to visibility), as we expected it to exert a larger influence due to the high vegetation levels at the study site. The adjacency effect might cause the smallest impact on LAI estimation due to the relatively high amount of dark vegetation and homogeneity of each bamboo field (planted in rows).

\subsection{LAI variability within one image}

The LAI variability with time for the investigated study site is shown in Fig. 6a. LAI was obtained for the three different VI values via ATCOR

Table 4

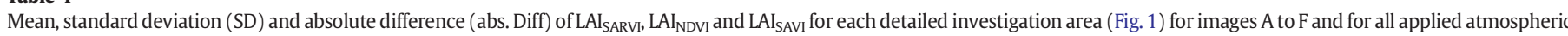
correction schemes.

\begin{tabular}{|c|c|c|c|c|c|c|c|c|c|c|c|c|}
\hline \multirow[b]{3}{*}{ Image } & \multicolumn{4}{|c|}{$\underline{\mathrm{LAI}_{\mathrm{NDVI}}}$} & \multicolumn{4}{|c|}{$\underline{\mathrm{LAI}_{\mathrm{SAVI}}}$} & \multicolumn{4}{|c|}{$\mathrm{LAI}_{\text {SARVI }}$} \\
\hline & \multirow{2}{*}{\multicolumn{2}{|c|}{ Mean \pm SD }} & \multicolumn{2}{|c|}{ abs. Diff } & & & \multicolumn{2}{|c|}{ abs. Diff } & & & \multicolumn{2}{|c|}{ abs. Diff } \\
\hline & & & Mean & Max & \multicolumn{2}{|c|}{ Mean \pm SD } & Mean & Max & \multicolumn{2}{|c|}{ Mean \pm SD } & Mean & Max \\
\hline \multicolumn{13}{|l|}{ 4. BRDF (yes vs. no) } \\
\hline $\mathrm{A}(04.08 .2011)$ & 3.12 & 0.13 & 0.18 & 1.40 & 2.58 & 0.14 & 0.19 & 0.56 & 2.03 & 0.16 & 0.23 & 0.89 \\
\hline $\mathrm{B}(05.12 .2011)$ & 2.19 & 0.00 & 0.00 & 0.04 & 2.11 & 0.01 & 0.01 & 0.06 & 1.96 & 0.03 & 0.04 & 0.21 \\
\hline C (28.01.2012) & 1.83 & 0.00 & 0.00 & 0.00 & 2.00 & 0.00 & 0.00 & 0.00 & 2.17 & 0.00 & 0.00 & 0.00 \\
\hline $\mathrm{D}(04.03 .2012)$ & 1.81 & 0.00 & 0.00 & 0.04 & 1.87 & 0.02 & 0.03 & 0.09 & 1.90 & 0.06 & 0.08 & 0.34 \\
\hline $\mathrm{E}(02.05 .2012)$ & 2.11 & 0.01 & 0.01 & 0.45 & 1.82 & 0.08 & 0.11 & 0.31 & 1.41 & 0.11 & 0.15 & 0.60 \\
\hline$F(06.08 .2012)$ & 3.66 & 0.01 & 0.01 & 0.06 & 2.92 & 0.15 & 0.21 & 0.43 & 2.21 & 0.25 & 0.35 & 1.05 \\
\hline Mean $A$ to $F$ & 2.45 & 0.02 & 0.03 & 0.33 & 2.22 & 0.07 & 0.09 & 0.24 & 1.95 & 0.10 & 0.14 & 0.52 \\
\hline \multicolumn{13}{|c|}{ 5. Topography (AT2 vs. AT3) } \\
\hline $\mathrm{A}(04.08 .2011)$ & / & 0.11 & 0.15 & / & / & 0.06 & 0.09 & / & / & 0.05 & 0.07 & / \\
\hline $\mathrm{B}(05.12 .2011)$ & / & 0.07 & 0.10 & / & / & 0.04 & 0.06 & / & / & 0.04 & 0.06 & / \\
\hline C (28.01.2012) & / & 0.04 & 0.06 & / & / & 0.03 & 0.04 & / & / & 0.16 & 0.22 & / \\
\hline $\mathrm{D}(04.03 .2012)$ & / & 0.02 & 0.03 & / & / & 0.01 & 0.02 & / & / & 0.23 & 0.32 & / \\
\hline $\mathrm{E}(02.05 .2012)$ & / & 0.03 & 0.05 & / & / & 0.02 & 0.03 & / & / & 0.02 & 0.03 & / \\
\hline$F(06.08 .2012)$ & / & 0.04 & 0.05 & I & / & 0.03 & 0.04 & l & / & 0.04 & 0.05 & / \\
\hline Mean A to F & / & 0.05 & 0.07 & / & / & 0.03 & 0.05 & / & / & 0.09 & 0.13 & / \\
\hline
\end{tabular}




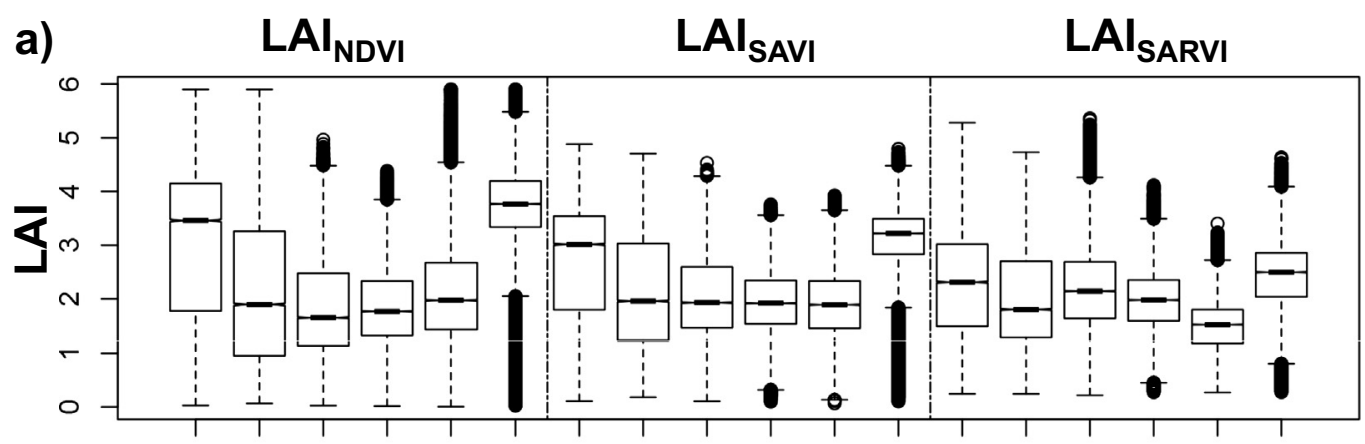

$\begin{array}{llllllllllllllllllllllll}(A) & (B) & (C) & \text { (D) } & (\mathrm{E}) & \text { (F) } & \text { (A) } & \text { (B) } & \text { (C) } & \text { (D) } & \text { (E) } & \text { (F) } & \text { (A) } & \text { (B) } & \text { (C) } & \text { (D) } & \text { (E) } & \text { (F) }\end{array}$

b)

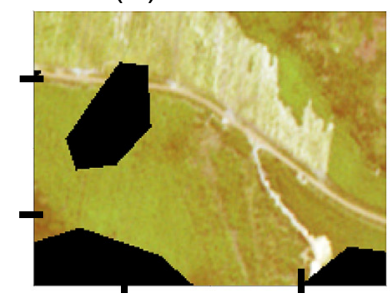

(D) 04.03 .2012

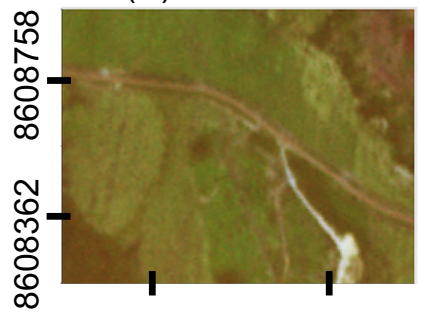

(B) 05.12 .2011

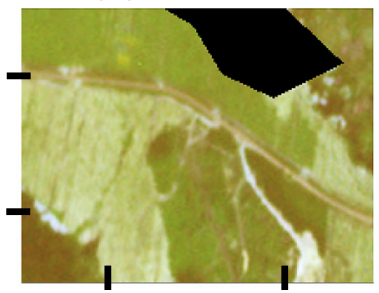

(E) 02.05 .2012

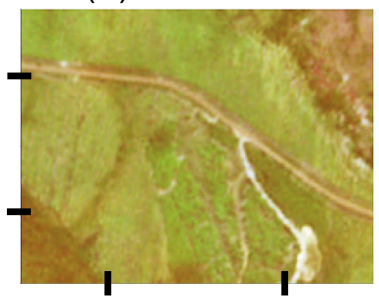

(C) 28.01.2012

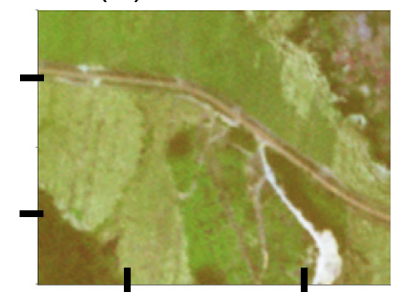

(F) 06.08 .2012

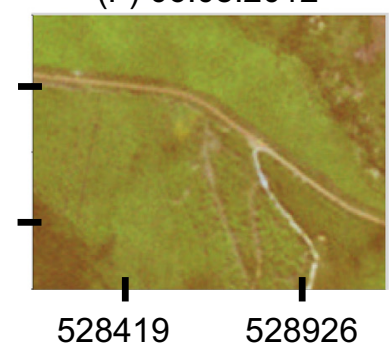

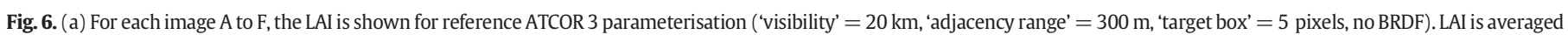

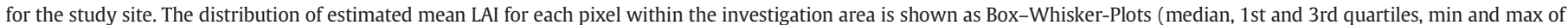
distribution and outliers). LAI estimation was based on NDVI, SAVI and SARVI. (b) RGB composite of images A to F (enhanced contrast), with light areas indicating bamboo harvest.

parameterisation using reference parameters. Whereas the overall LAI development of $\mathrm{LAI}_{\mathrm{NDVI}}$, $\mathrm{LAI}_{\mathrm{SAVI}}$ and $\mathrm{LAI}_{\mathrm{SARVI}}$ is very similar, the magnitude of LAI variation over time decreases from $\mathrm{LAI}_{\mathrm{NDVI}}$ to LAI $\mathrm{SARVI}_{\mathrm{S}}$ (Fig. 6a). Considering $\mathrm{LAI}_{\mathrm{NDVI}}$, the median LAI value decreases for the investigation area from $A(3.5)$ to $B(1.9)$, reaches a minimum at $C$ (1.8) and $\mathrm{D}$ (1.8), and increases again at images $\mathrm{E}$ (2.1) and $\mathrm{F}$ (3.8) (Fig. 6a). In contrast, the development of $\mathrm{LAI}_{\mathrm{SARVI}}$ over time is more consistent, yielding LAI medians of 2.2 (A), 1.8 (B), 2.1 (C), 2.0 (D), 1.5 (E) and $2.5(\mathrm{~F})$.

In order to determine which VI best represents the most plausible LAI development pattern for our investigation area (Fig. 1), we analysed the RGB composite images (Fig. 6b). Additionally, we must also take into

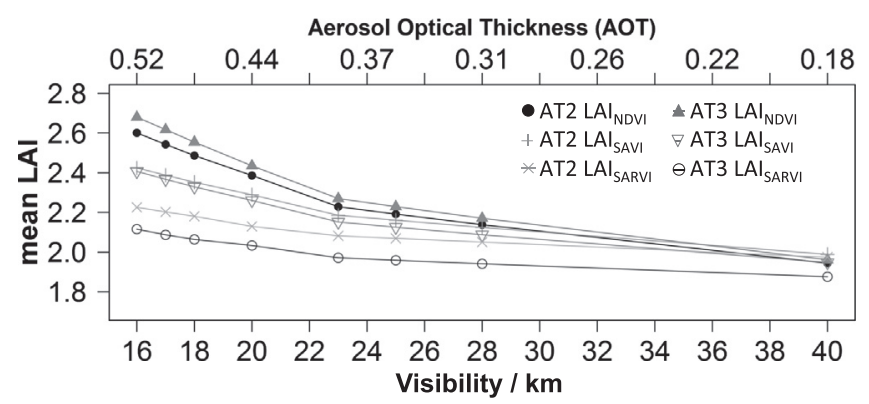

Fig. 7. Relationship between changes in mean LAI due to changes in meteorological range based on mean LAI values computed over images A to F (IA 1). account that only the LAI of the bamboo fields surrounding the waste disposal area is prone to change over the studied time period. Surrounding bamboo fields make up about $54 \%$ of the investigation area. We assume that LAI for the secondary forest and mature bamboo strip are constant over the investigated time period. Fig. 6b illustrates that bamboo harvest took place in the northern section of image $\mathrm{A}$ ( area $=18.5 \%$ of illustrated study site) and in the southern section of image B (area = $35.8 \%$ of study site), which should result in the lowest LAI values for the time-series, which are not compensated for by the regrowth of the northern bamboo field. Taking harvesting in the area into account, we estimate that LAI decreases from images A to B by about 20\%. Looking at our results, the percentage of LAI decrease from $A$ to $B$ is $45.2 \%$ for $\mathrm{LAI}_{\mathrm{NDVI}}, 35.0 \%$ for $\mathrm{LAI}_{\mathrm{SAVI}}$, and $14.3 \%$ for $\mathrm{LAI}_{\mathrm{SARVI}}$ (Fig. $6 \mathrm{a}$ ).

For images $\mathrm{C}$ to $\mathrm{F}$, the harvested bamboo fields regrow continuously, reaching their maximum growth level in image F. Comparing the RGB images of $\mathrm{E}$ and $\mathrm{F}$, we can see that there is stronger vegetation development than in previous time steps. This faster plant development might be due to improved water availability during that time period. The period from December 2011 to April 2012 was one of relatively low mean monthly precipitation $(42.3 \mathrm{~mm})$, whereas the mean monthly precipitation $(127.0 \mathrm{~mm})$ was higher in the period from May 2012 to August 2012 (ICEA, 2013). The LAI values shown on image F should be higher than those in image A. Based on previous explanations; we can see that the development pattern of LAI $\mathrm{SAVI}_{\text {I }}$ matches best with the harvest, plant growth and climate conditions. LAI SAVI $_{\text {I }}$ describes the LAI decrease from $A$ to $B$, and leaf LAI for images $C$ to $E$ is quite constant (even though we assumed a small LAI increase), with the highest LAI values being 
achieved by image F-values which were slightly higher than for image A. $\mathrm{LAI}_{\mathrm{SAVI}}$ additionally provides the smallest amount of outliers. $\mathrm{LAI}_{\mathrm{NDVI}}$ has highly variable LAI values, tending towards an overestimation of LAI. LAI $I_{\text {SARVI }}$ also illustrates the assumed LAI development over time, but has an unexplainable LAI decrease from $C$ to $E$. The LAI decrease from $C$ to $E$ of approx. 0.6 may be due to small variations in water availability, which were captured by $\mathrm{LAI}_{\mathrm{SARVI}}$. However, we cannot verify this with the daily precipitation data available (data not shown).

The interpretability of LAI changes between time-series steps depends on LAI estimation uncertainty due to ATCOR parameterisation. It is assumed that LAI changes between time steps are only detectable when they are greater than the highest uncertainty range (SD) of LAI estimation. The LAI uncertainty range depends on the uncertainty of ATCOR model parameter selection, where higher parameter uncertainty ranges generally cause higher LAI uncertainties than smaller parameter uncertainty. ATCOR parameter uncertainty is most influenced by 'visibility' uncertainty. If we look on results from using ATCOR 3, then LAI variations could be detected when mean $\mathrm{LAI}$ change is $>0.26$ for $\mathrm{LAI}_{\mathrm{NDVI}}$, $>0.16$ for $\mathrm{LAI}_{\mathrm{SAVI}}$, and $>0.09$ for $\mathrm{LAI}_{\mathrm{SARVI}}$ (Tables 3 and 4 ). $\mathrm{LAI}$ changes within the SD of LAI uncertainty are random and can be called 'noise', which is not interpretable. In the case of $\mathrm{LAI}_{\mathrm{NDVI}}$ and $\mathrm{LAI}_{\mathrm{SAVI}}$, only the LAI change from $A$ to $B$ and $E$ to $F$ is outside the LAI estimation uncertainty range. In contrast, the changes of $\mathrm{LAI}_{\mathrm{SARVI}}$ are within the estimated LAI uncertainty range. Considering, that the uncertainty of visibility will be smaller than our assumed uncertainty range of 'visibility' for many applications, smaller LAI uncertainties and better detectability of LAI changes between time steps of a time-series can be expected.

Additionally, LAI estimation variability seems to depend on vegetation coverage and density. This becomes apparent when we consider the standard deviation (SD) dynamics of LAI estimation for each image of the time series ('visibility' variation, ATCOR 3, Fig. 8). The smallest LAI variability due to atmospheric correction reveals $\mathrm{LAI}_{\text {SARVI }}$ with a SD maximum $\left(\mathrm{SD}_{\max }\right)$ of 0.44 , which is directly followed by $\mathrm{LAI}_{\mathrm{SAVI}}\left(\mathrm{SD}_{\max }=\right.$ $0.45)$ and $\mathrm{LAI}_{\mathrm{NDVI}}\left(\mathrm{SD}_{\max }=1.11\right)$ (Fig. 8). Generally, the highest LAI variability due to atmospheric correction occurs in densely vegetated areas, as seen when we jointly consider and evaluate Figs. 6 and 8. This is what we expected from the known relationship between VI and vegetation coverage (LAI) as well as 'visibility' (decreasing 'visibility' lowers VI), where the atmospheric influence is stronger on densely vegetated areas and therefore leads to a greater variation of VI (Kaufman \& Tanré, 1992). An additional source of LAI uncertainty arises from the canopy background influences caused by soil. NDVI does not account for these background influences in contrast to the better-performing soil correction of VI (SAVI, SARVI) (Huete et al., 1997). LAI well for all studied images of the time-series, having the most robust VI in relation to atmospheric correction. Therefore, the stable small LAI uncertainty over time indicates that it is beneficial to use SARVI for LAI estimation for time-series analysis. LAI $_{\mathrm{NDVI}}$ had the highest LAI estimation uncertainty dynamic over time compared to $\mathrm{LAI}_{\mathrm{SAVI}}$, which had smaller LAI variation for the different images (Fig. 8). The mean \pm SD of LAI of all studied images is summarised in Tables 3 and 4.

\subsection{LAI differences within the overlapping area of successive images} recorded on the same date

After describing LAI variability for several parameterisations of the ATCOR model, the second analysis aims to investigate the overlapping area of successive satellite images from the same point in time. Theoretically, image values from matching positions, which have been atmospherically corrected and are from the same date should return identical image values for the analysed area. If these overlapping values differ, then the retrieved LAI estimates would be different as well. In this case, the question arises of how best to combine these images in order to obtain true LAI estimations that accurately represent nature. Low LAI uncertainty for two successive overlapping image pairs is a prerequisite for mosaicking. The mosaicked images are required in SVAT modelling when the study site is mapped by several satellite images. This poses the question: do overlapping areas of two images from the same time provide equal LAI values when they experience atmospheric correction with identical parameter selection? To answer this, the $\mathrm{LAI}_{\mathrm{NDVI}}, \mathrm{LAI}_{\mathrm{SAVI}}$ and $\mathrm{LAI}_{\mathrm{SARVI}}$ of an overlapping area of about $0.8 \mathrm{~km}^{2}$ (C (north) and $\mathrm{H}$ (south) from 28.01.2012 and $\mathrm{F}$ (north) and G (south) from 06.08.2012) were compared. The overall distribution of $\mathrm{LAI}_{\mathrm{NDVI}}, \mathrm{LAI}_{\mathrm{SAVI}}$ and $\mathrm{LAI}_{\mathrm{SARVI}}$ displays a similar pattern for our examined study site (Figs. 9b and $10 \mathrm{~b}$ ). The mean of $\mathrm{LAI}_{\text {SARVI }}$ ranges from $2.3(\mathrm{C})$ to $2.2(\mathrm{H})$. Both $\mathrm{LAI}_{\mathrm{SAVI}}$ and $\mathrm{LAI}_{\mathrm{NDVI}}$ provide a similar LAI value for both images ( $\mathrm{C}$ and $\mathrm{H}$ ), with mean LAI of 2.1 and 1.9, respectively (Fig. 9). Each LAI retrieval function resulted in similar LAI estimates for the selected images. In the same way, the comparison of images $\mathrm{F}$ and $\mathrm{G}$ leads to analogous $\mathrm{LAI}$ values for $\mathrm{LAI}_{\text {SARVI }}(2.2)$, $\mathrm{LAI}_{\mathrm{SAVI}}$ (2.6) and $\mathrm{LAI}_{\mathrm{NDVI}}$ (3.0) (Fig. 10). However, in the case of images $\mathrm{F}$ and $\mathrm{G}$, the LAI values increased in the order $\mathrm{LAI}_{\mathrm{SARVI}}$, $\mathrm{LAI}_{\mathrm{SAVI}}$ to $\mathrm{LAI}_{\mathrm{NDVI}}$.

Subsequently, one image was mathematically subtracted from the other in order to obtain the absolute difference between both images. The mean absolute LAI difference between images $\mathrm{C}$ and $\mathrm{H}$ equates to $\mathrm{LAI}_{\mathrm{SARVI}}=0.10(\max =1.0), \mathrm{LAI}_{\mathrm{SAVI}}=0.08(\max =$ $0.89)$ and $\mathrm{LAI}_{\mathrm{NDVI}}=0.11(\mathrm{max}=1.10)$ (Fig. 9). Both mean and maximum differences for images $\mathrm{C}$ and $\mathrm{H}$ are larger than for images $\mathrm{F}$ and $\mathrm{G}$. Mean absolute difference of LAI is equal to $\mathrm{LAI}_{\mathrm{SARVI}}=0.03(\mathrm{max}=$ $0.22), \mathrm{LAI}_{\mathrm{SAVI}}=0.03(\max =0.24)$ and $\mathrm{LAI}_{\mathrm{NDVI}}=0.04(\max =0.39)$ for images $\mathrm{F}$ and $\mathrm{G}$ (Fig. 10). The highest LAI differences generally occurred in areas of higher and denser vegetation (e.g. mature bamboo) and at their border to lower vegetation. This is illustrated by the LAI frequency distributions of the paired images through the mismatch of LAI curves at higher LAI values (Figs. 9b and 10b). The mismatch is most evident for $\mathrm{LAI}_{\mathrm{NDVI}}$ and the spatial illustration of absolute LAI differences with the highest LAI differences in areas where dense vegetation occurs (Figs. 9a and 10a, in consideration of Fig. 1). Additionally, larger differences for images $\mathrm{C}$ and $\mathrm{H}$ are observable at object borders, being visibly as clear lines in the noisy 'absolute difference' of both images (Fig. 9a). Those LAI differences especially being visible at vegetated areas are caused by the ATCOR algorithm, which uses the sun position of the centre coordinate to define the atmospheric correction function for each pixel of the whole image (ERDAS \& Geosystems, 2011). However, the sun position influence on atmospheric correction is smallest at nadir view, and increases towards the satellite image edge, where the study site is located. For instance, for images $\mathrm{G}$ and $\mathrm{F}$ the sun elevation angle difference at the study site is $0.1^{\circ}$ and is twice as large for images $C$ and $\mathrm{H}\left(0.2^{\circ}\right)$ compared to the sun elevation angle at image centre. In spite of a successfully applied co-registration of images $\mathrm{C}$ and $\mathrm{H}$, both images still seem to have a small offset in the $\mathrm{x}$ direction. The successful co-registration of both images was confirmed by characteristic pixel reflectance patterns that can be found in both images. Thus, this image offset appears not as a real geographic shift, but more as a smearing of reflectance values at object borders (e.g. vegetation-bare soil). According to the results of Section 6.3.2 (BRDF), this smearing cannot be explained by anisotropic reflectance behaviour, but rather by shadows in the image. When we compared the image pairs ( $\mathrm{C}$ and $\mathrm{H}$ versus $\mathrm{F}$ and $G$ ), we found that the sensor images of the earth's surface were quite different to what the observation geometry suggested. Images $\mathrm{C}$ and $\mathrm{H}$ were acquired in January with an azimuth angle difference between illumination and observation direction of $165^{\circ}$. This means that the satellite is directly pointed towards the area of shadowed sunlight (shadowed by the plants). Images $\mathrm{F}$ and $\mathrm{G}$ were acquired in August with an azimuth angle difference of less than $90^{\circ}$. A large part of the shadowed side of the plants is invisible to the satellite, as results suggested it agrees with the area shadowed by the line of sight to the satellite. Accordingly, there are very different orientations of the object shadows (e.g. vegetation) in relation to the line of sight to the sensor between both image pairs. Moreover, in the case of images F and G, the direction of object shadows to the line of sight to the satellite did not greatly change during satellite movement. From one image to the 

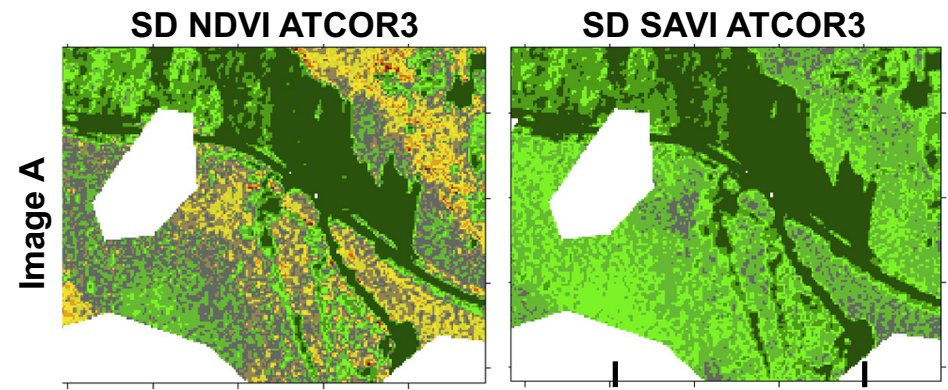

\section{SD SARVI ATCOR3}
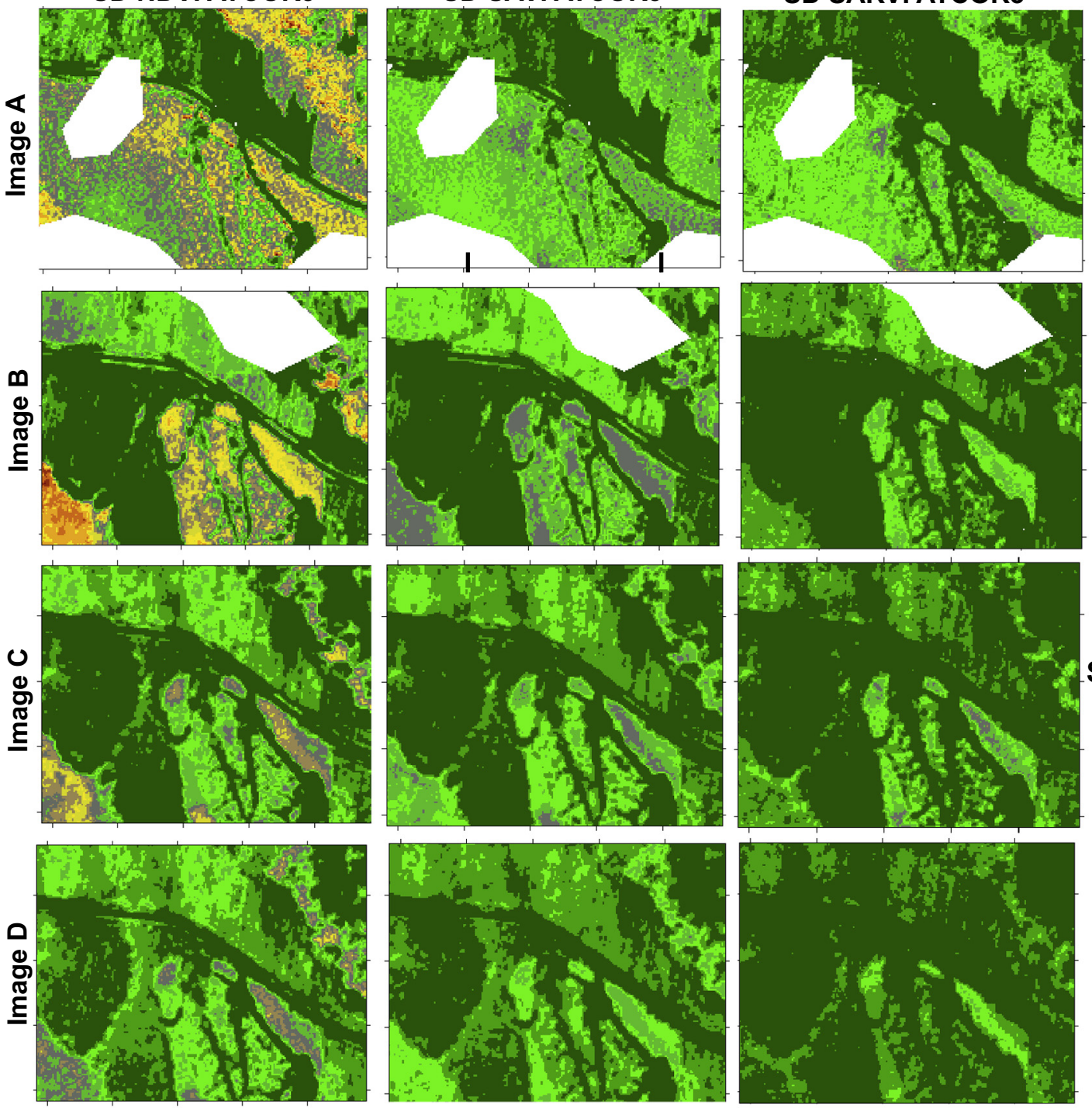

SD (LAI)
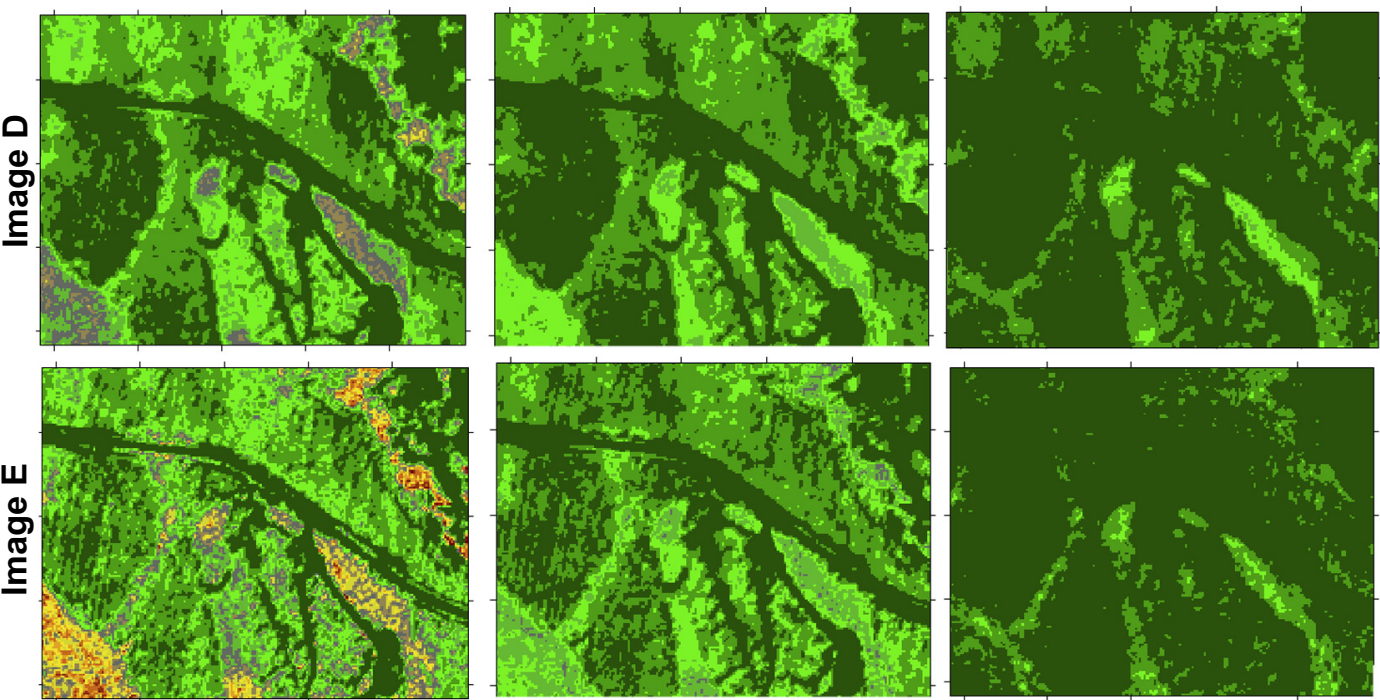

1.4
1.2
1.0
0.8
0.6
0.4
0.2
0
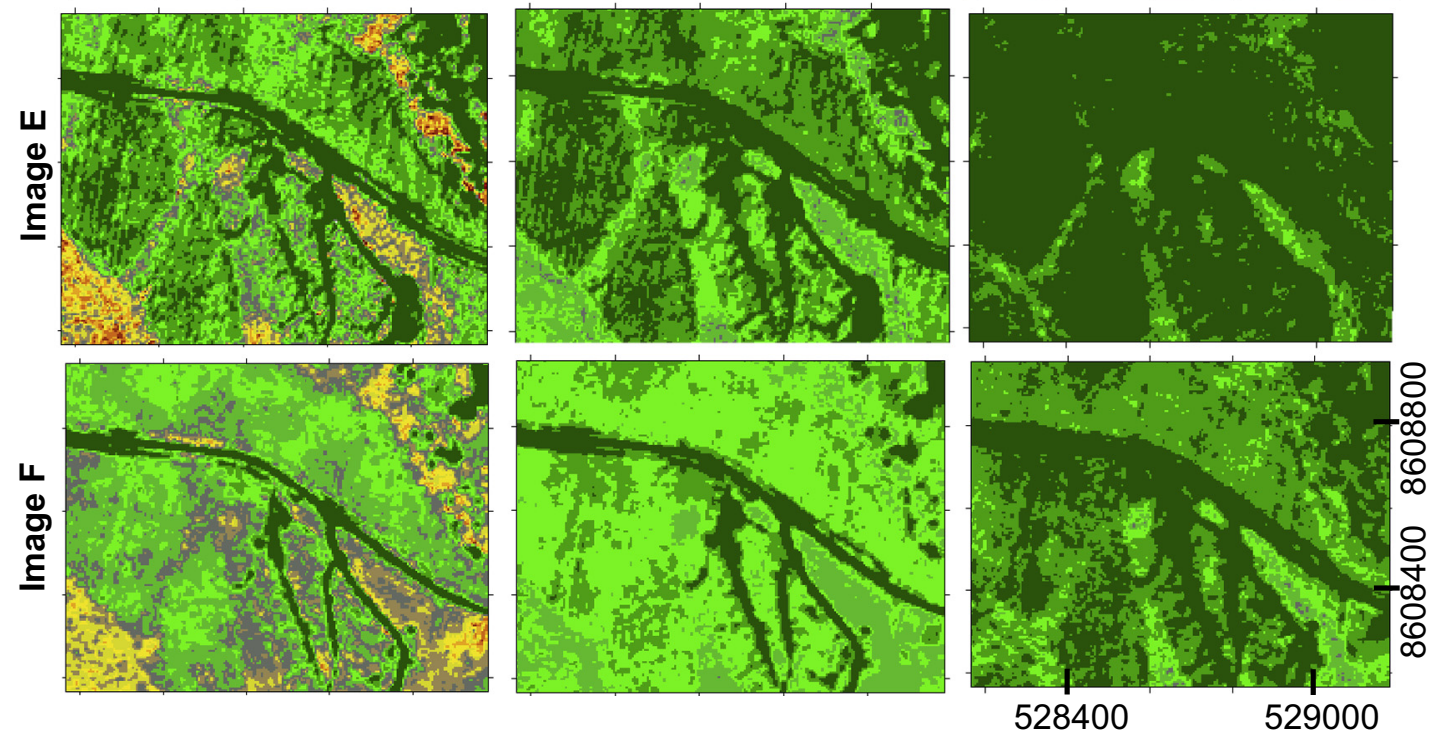

Fig. 8. Standard deviation (SD) of LAI based on VI of all parameterisations of meteorological range ('visibility') for images A to F with ATCOR 3; white areas designate removed clouds; legend for image dates can be found in Table 1 (Copyright DLR 2011 and 2012). 
a)

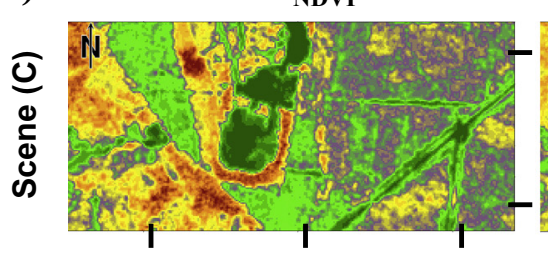

$\mathbf{L A I}_{\text {SAVI }}$

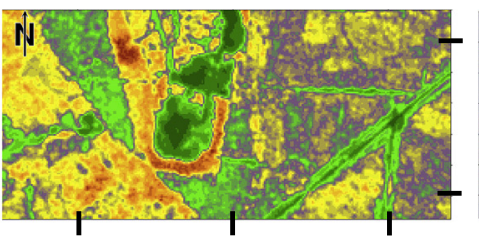

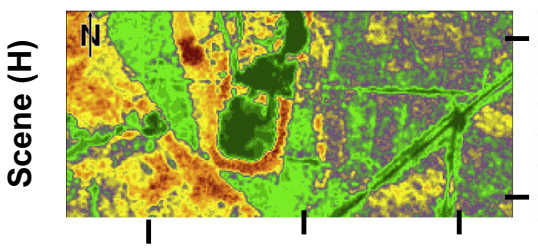
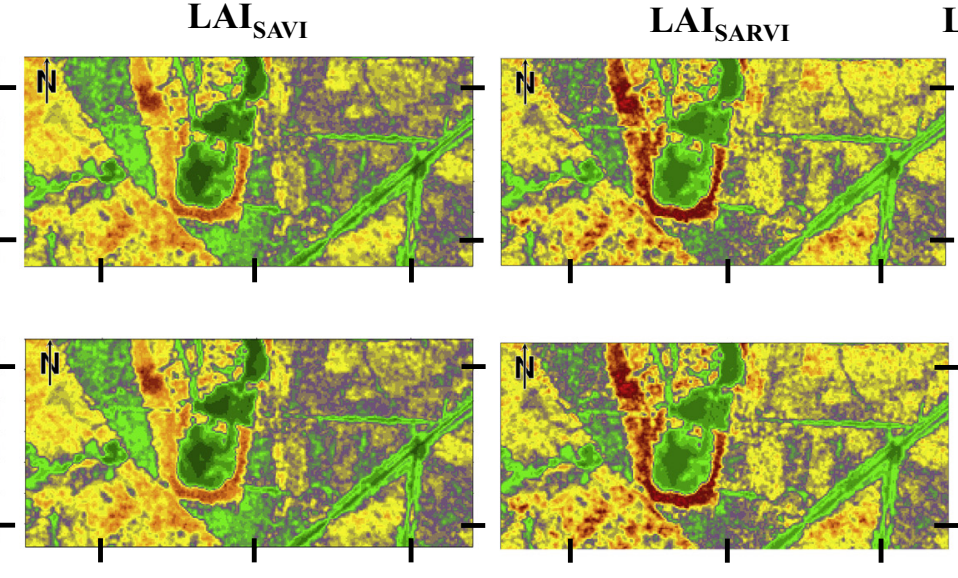

LAI
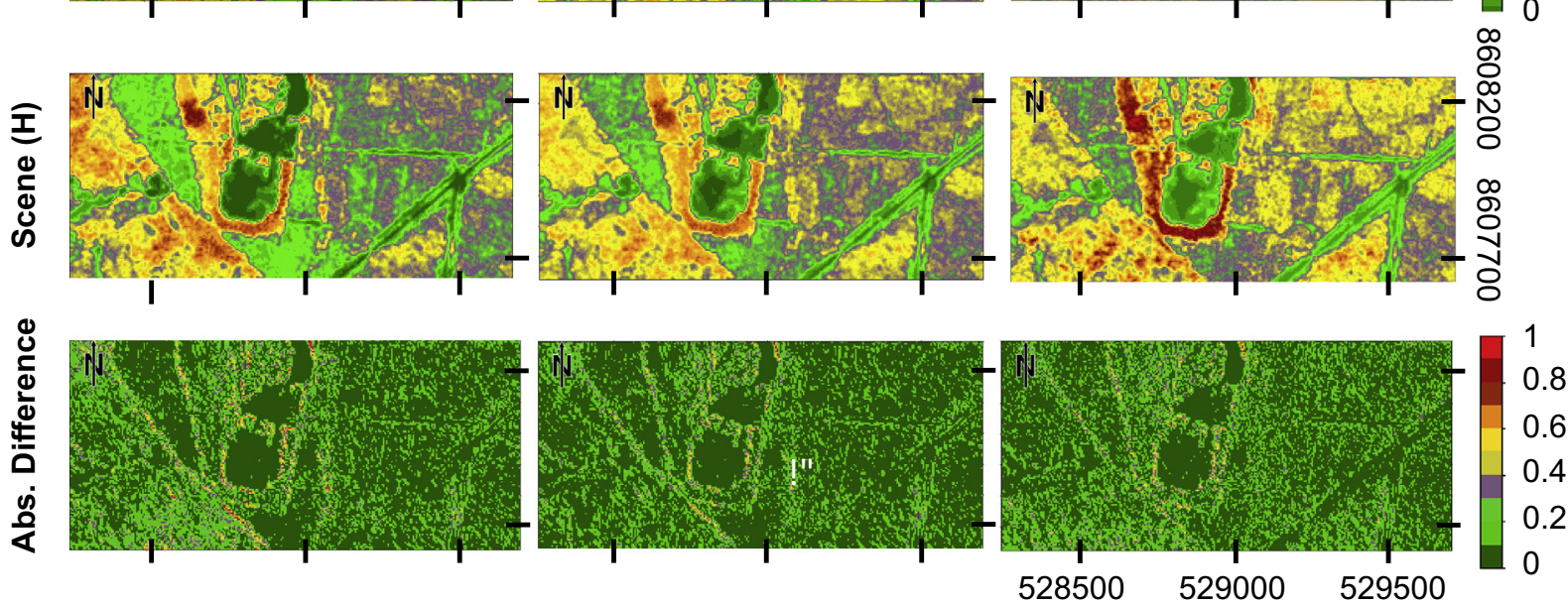

b)

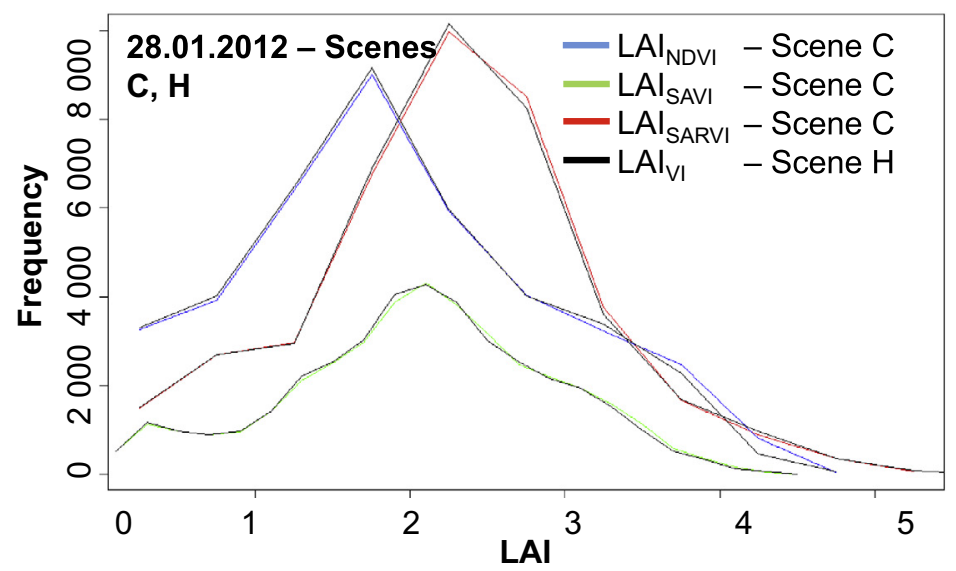

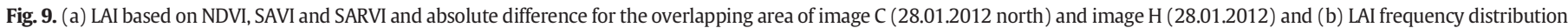
(Copyright DLR 2012). Atmospheric correction applied to images C and H: ATCOR 3, 'visibility' $=20$ km, 'target box' $=5$ pixels, 'adjacency' $=300$ m.

next, the sensors tilt and the sun azimuth angle changes by about only $0.41^{\circ}$ and $0.15^{\circ}$, respectively. This constellation causes the small smearing effect during satellite movement. In contrast, in the case of images $\mathrm{C}$ and $\mathrm{H}$, the direction of the object shadow to the line of sight changes more (sensor tilt $=0.44^{\circ}$, sun azimuth $=0.70^{\circ}$ ) during satellite movement. For this reason, the smearing effect is more observable. The extent of object shadow shift is undoubtedly dependent on vegetation height, since the smearing is especially visible in areas with high vegetation density and canopy height. In addition, this assumption is supported by the findings of Verrelst, Schaepman, Koetz, and Kneubühler (2008) emphasizing that VI values are sensitive to sensor viewing angle.

In general, calculation of VI from the atmospherically corrected images yields results with relatively low LAI differences, where the mean LAI difference (for $\mathrm{LAI}_{\mathrm{SARVI}}, \mathrm{LAI}_{\mathrm{SAVI}}, \mathrm{LAI}_{\mathrm{NDVI}}$ ) for noisy images did not exceed 0.1 . The maximum LAI differences are $<1$ and occur mainly at object borders. These results are valid for each of the VI used in LAI estimation equations (Eqs. 9-11). We expect that the mean LAI differences $(\leq 0.1$ to max. 1 ) for the overlaying image area are in the common LAI error range for ecological studies. For instance, the LAI standard error of direct field measurements (e.g. litter collection and allometry) for broad-leaf species ranges between 0.2 and 0.5 (Bréda, 2003).
Conclusively, it appears to be possible to jointly use the LAI values of two successive images in SVAT modelling through mosaicking.

\subsection{Evaluation of LAI uncertainty in the context of SVAT modelling}

The LAI of 3.2 is considered a typical LAI for the studied bamboo plantation. For this reason, the model sensitivity impact on annual interception, transpiration, evaporation and evapotranspiration (ET) was analysed relative to a reference LAI of 3.2. The sensitivity index (SI) for LAI changes $( \pm 0.1$ and \pm 0.5$)$ is medium for ET ( $\mathrm{SI}=-0.15$ and -0.12 ) and transpiration ( $\mathrm{SI}=0.12$ and 0.15 ). Sensitivity is high for interception (SI $=0.22$ and 0.22 ), and evaporation (SI $=-0.53$ and -0.49). Investigating Fig. 11, the sensitivity analysis revealed that for ET and evaporation the highest LAI sensitivities occur especially at low LAI values. Sensitivity of interception and transpiration is equal for the whole LAI range investigated. With increasing LAI, the model sensitivity decreases. This directional behaviour on the $\mathrm{X}$-axis (Fig. 11) was expected because model sensitivity is related to the natural relationship between leaf area and evapotranspiration, where the transition from a bare soil to a vegetated area causes a rapid increase in transpiration levels, a fast decrease in soil evaporation, but a continuous increase of 
a)

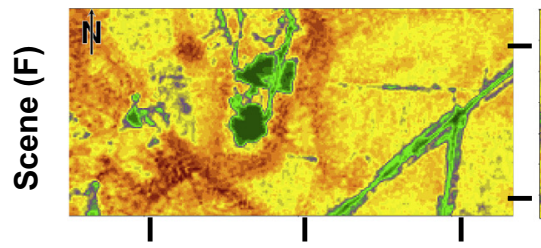

$\mathbf{L A I}_{\text {SAVI }}$

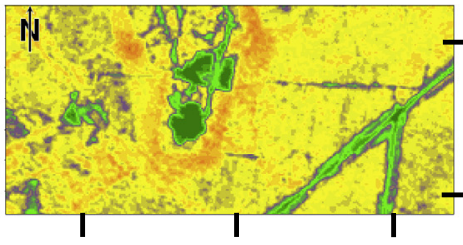

LAI $_{\text {SARVI }}$

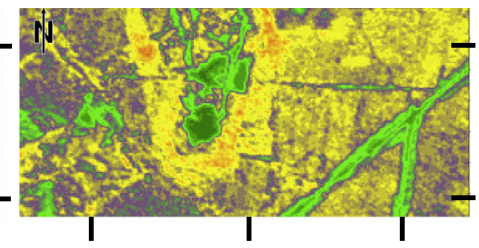

LAI

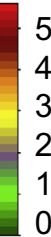

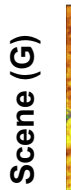
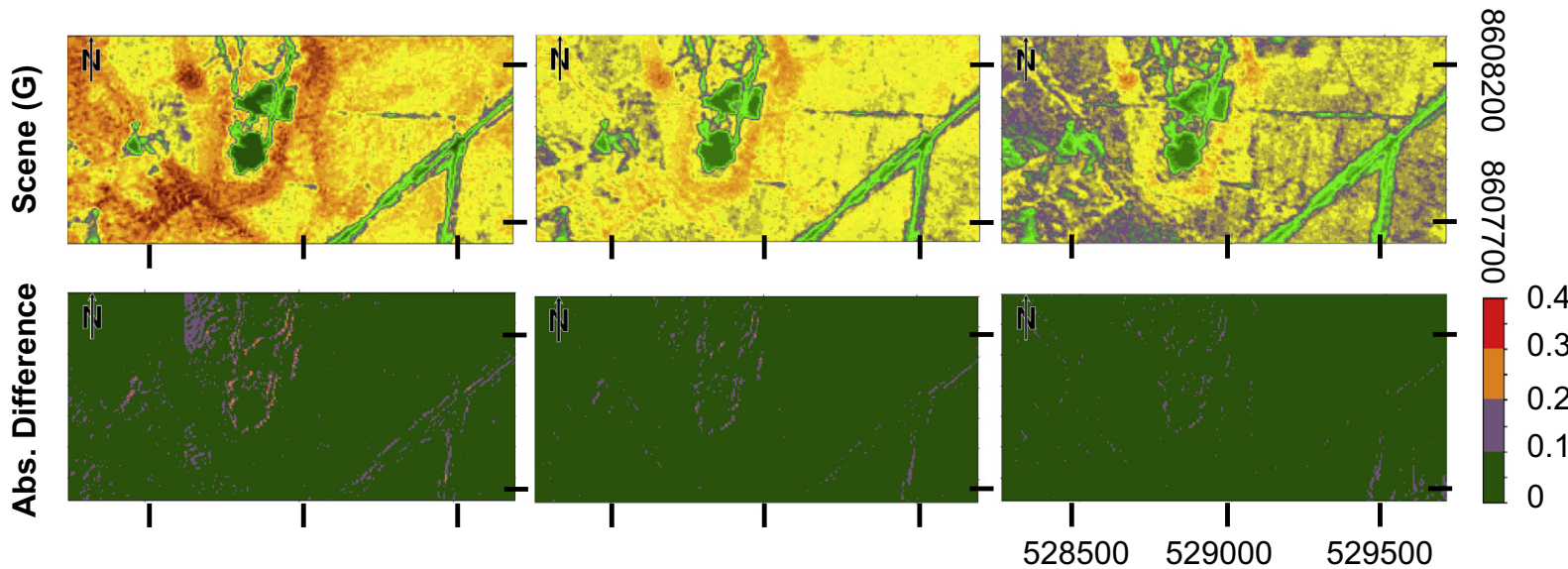

b)

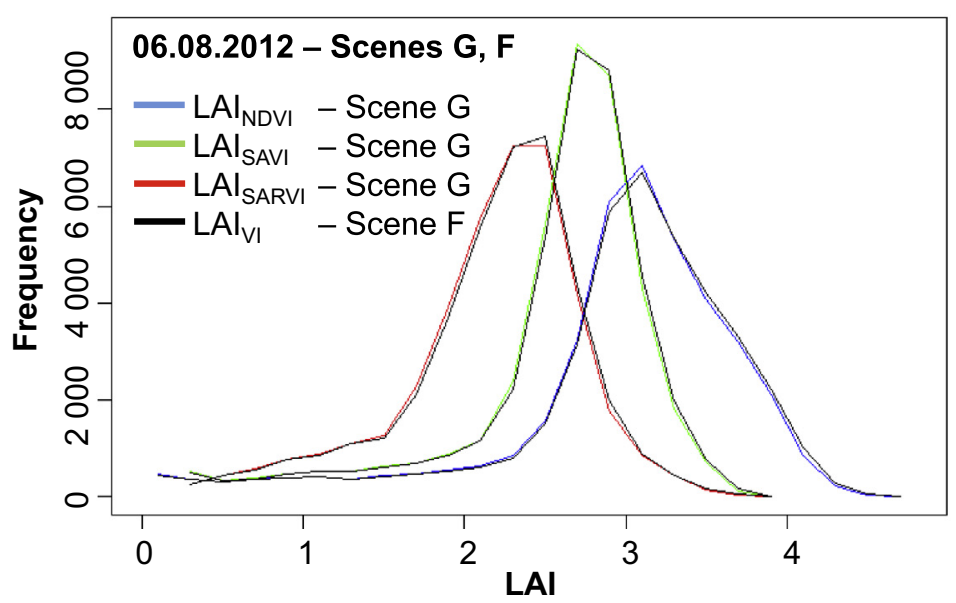

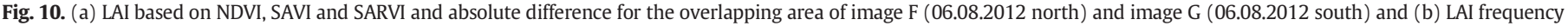
distribution (Copyright DLR 2012). Atmospheric correction applied to images F and G: ATCOR 3, 'visibility' $=20$ km, 'target box' $=5$ pixels, 'adjacency' $=300$ m.

interception loss. In this way, total evapotranspiration increases sharply during the initial phase of plant development and then asymptotically approaches a maximum at intermediate to high LAI values (Kergoat, 1998). Interception shows a strong linear relationship with LAI (Fig. 11).

Our results confirm the high LAI sensitivities of SVAT models to the water balance, as has been previously reported in other studies. For instance, LAI provided by MODIS time-series ranges from 2.5 to 5 (North America, temperate to continental humid climate). It results in yearly cumulative evapotranspiration values of around $400 \mathrm{~mm}$ to $600 \mathrm{~mm}$, respectively (Horn \& Schulz, 2010). At a native, humid, Eucalyptusdominated forest, it was found that the ecosystem changes from a net carbon source to a strong net carbon sink when LAI changed from 0.5 to 3.5 (Van Gorsel et al., 2011).

In the following section, we will investigate the consequences of the LAI uncertainty found in our study due to atmospheric correction for SVAT modelling with CoupModel. For simplicity, the SVAT model uncertainties are mostly given as a mean percentage change from the reference LAI. The error propagation from single band variations to SVAT model uncertainty is shown in Fig. 4. The LAI uncertainties arising from the systematic variation of a single ATCOR parameter translate into no CoupModel uncertainties (analysed versus reference LAI $=$ $3.2)$ if LAI uncertainty $\left(\overline{\mathrm{SD}}_{\text {min }}=0.00\right)$ is zero. The maximal occurring LAI uncertainty in our study ( $\mathrm{LAI} \overline{\mathrm{SD}}_{\max }=0.37, \mathrm{LAI}_{\mathrm{NDVl}}$, ATCOR 3 ) resulted in medium (transpiration $\pm 3.1 \%, \mathrm{ET} \pm 3.1 \%$ ) and high (interception $\pm 9.1 \%$, evaporation $\pm 11.8 \%$ ) mean CoupModel uncertainties (Tables 3 and 4). SVAT uncertainty increases with LAI uncertainty from $\mathrm{LAI}_{\mathrm{SARVI}}, \mathrm{LAI}_{\mathrm{SAVI}}$ to $\mathrm{LAI}_{\mathrm{NDVI}}$. For instance, the variation of 'visibility' (ATCOR 3) within the range (16-40 km) results in mean evaporation uncertainties of $\pm 3.3 \%$ for $\mathrm{LAI}_{\mathrm{SARVI}}$ (LAI $\left.\overline{\mathrm{SD}}=0.09\right) \pm 5.1 \%$ for $\mathrm{LAI}_{\mathrm{SAVI}}$ (LAI $\overline{\mathrm{SD}}=0.16$ ), and $8.6 \%$ for $\mathrm{LAI}_{\mathrm{NDVI}}$ (LAI $\overline{\mathrm{SD}}=0.26$ ) (compared with Tables 3 and 4). However, analysing Fig. 8 (ATCOR 3 ) illustrates that (especially for densely vegetated areas) maximum LAI variations can reach much higher uncertainties $\mathrm{SD}_{\max }=1.4$ for $\mathrm{LAI}_{\mathrm{NDVI}}, 0.5$ for $\mathrm{LAI}_{\mathrm{SAVI}}$, and 0.5 for $\mathrm{LAI}_{\mathrm{SARVI}}$. In best-case scenario for $\mathrm{LAI}_{\mathrm{SARVI}}$, a LAI uncertainty of $+0.5 /-0.5$, compared to reference $\mathrm{LAI}=3.2$, causes an increase or decrease of about $-2.5 \% /+5.8 \%$ for ET, and $-13.1 \% /$ $+18.8 \%$ for evaporation (Fig. 11). Taking into account the bamboo plantation size of $8 \mathrm{~km}^{2}$ and the local climate $\left(1600 \mathrm{~mm}\right.$ year $\left.{ }^{-1}\right)$, the LAI increase or decrease by 0.5 means, in the case of evapotranspiration, that per year approx. $3.2 \times 10^{8} 1$ of water can be additionally held in the system 


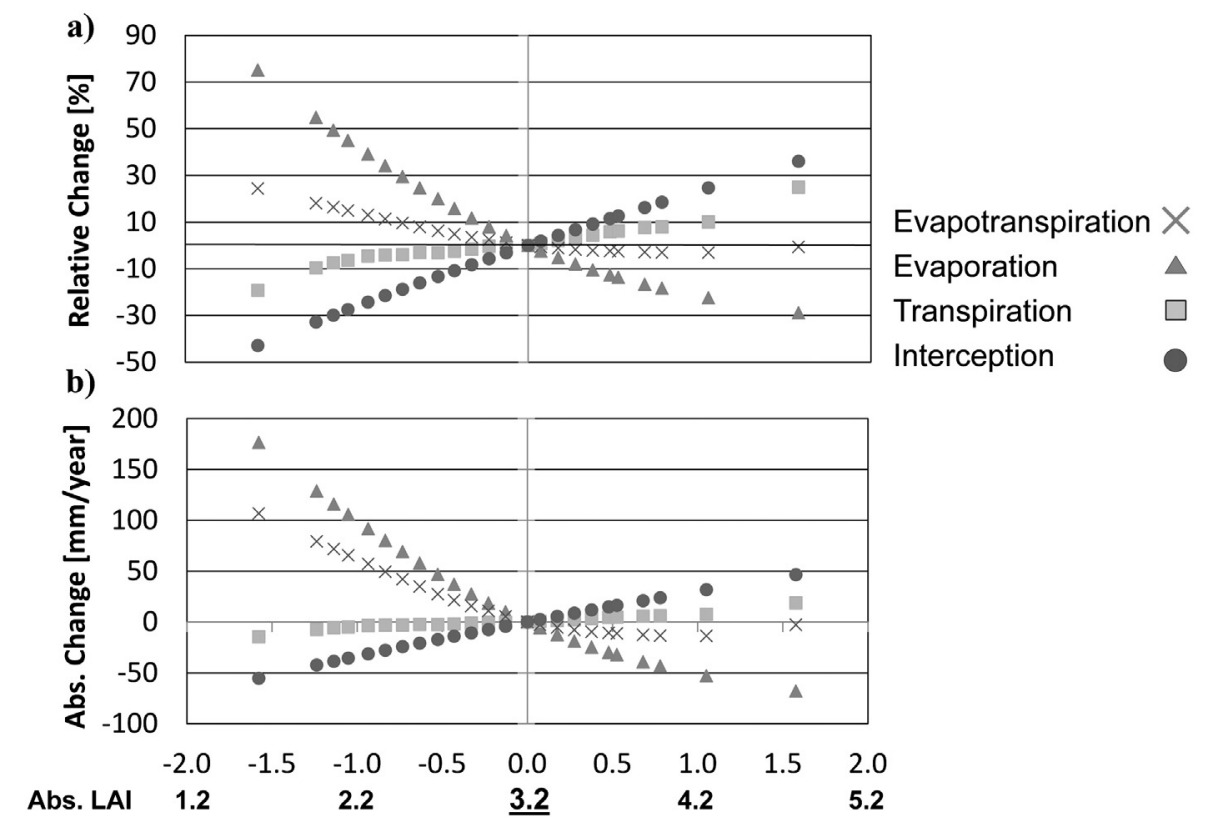

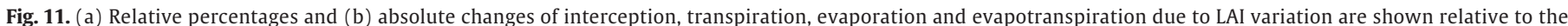
reference LAI value of 3.2 .

or approx. $7.4 \times 10^{8} 1$ of water per year are additionally lost into the atmosphere.

In order to rank LAI variability in this context, it is helpful to consider that the typical LAI for biomes (no desert, tundra) generally ranges from 3 to 19 (Asner, Scurlock, \& Hicke, 2003). However, in many situations, the uncertainty of 'visibility' parameter in ATCOR will be smaller than the 'visibility' variation range used in this study. There are resulting smaller LAI uncertainties and therefore smaller SVAT model uncertainties.

In contrast, the ATCOR parameter variations of 'adjacency range' and 'target box' are inconsequential for SVAT modelling - causing variations of around $0 \%$.

The mean LAI uncertainty (SD) that appears on overlapping areas of two successive images that have been similarly atmospherically corrected is LAI SD $<0.1$. This LAI variability leads to SVAT model uncertainty of $\pm 0.9 \%$ for ET, $\pm 2.5 \%$ for interception, $\pm 3.3 \%$ for evaporation, and $\pm 0.7 \%$ transpiration (Figs. 9 and 10 ). The resultant SVAT uncertainty is generally in an acceptable range for SVAT modelling.

Nevertheless LAI uncertainty and thus impact on SVAT modelling might be higher. For instance, Mannschatz and Dietrich (2013) showed that a non-systematically controlled atmospheric correction, which is the case in most practical applications, can yield LAI uncertainties (mean SD) from 0.1 to 0.5 and from 0.0 to 1.2 for $\mathrm{LAI}_{\mathrm{NDVI}}$ and $\mathrm{LAI}_{\mathrm{SAVI}}$, respectively. Mean LAI variations of $\pm 0.5-1.2$ already result in meaningful SVAT uncertainties of $\pm 4.2-9.9 \%$ for ET, and $\pm 16.0-38.5 \%$ for evaporation.

\section{Conclusions}

We investigated the influence of atmospheric correction with ATCORs 2 and 3 upon LAI estimations based on NDVI, SAVI and SARVI. Therefore, ATCOR parameters ('visibility', 'target box', 'adjacency', BRDF, topography) were varied systematically. The results highlight that different atmospheric correction parameterisations lead to different LAI estimations for one specific image. The order of ATCOR parameter influence on LAI estimation might be different for diverse study areas, where a more heterogeneous site can lead to larger topography and adjacency effects. However, visibility is assumed to always have the largest influencing capacity on LAI estimation. To account for site-specific differences, we suggest using ATCOR 3 for atmospheric correction. Our results show that the application of ATCOR 3 leads to more stable LAI estimations (similar or smaller LAI SD compared to ATCOR 2 application). For ATCOR model parameterisation, we recommend taking meteorological measurements at climate stations as a first estimate for selection of the 'visibility' parameter (highest influential parameter), which is then verified on known dense dark vegetation (DDV) pixel spectral characteristics in the ATCOR spectral investigation module. The ATCOR standard values can then be used for definition of an 'adjacency range' and size of a 'target box', since the influence on LAI estimation is negligible when using ATCOR 3. We additionally suggest applying a BRDF correction, since the influence on LAI estimation varies widely from 'none' to 'high' between the satellite images, depending on illumination and satellite viewing geometry.

The LAI estimations based on different VI leads to the conclusion that use of a more robust VI (e.g. SAVI and SARVI) is preferable to the use of NDVI, in order to allow stable LAI estimation. Our results reveal that the performance of SARVI is slightly superior to that of SAVI. The advantage of SARVI compared to SAVI is a smaller LAI estimation sensitivity to the ATCOR parameter 'visibility'. Furthermore, LAI changes from one timestep to another are more easily detectable with SARVI-based LAI estimates than with SAVI-based estimates, due to smaller SD values.

In addition to the single image analysis of atmospheric correction influence on LAI, we investigated if two consecutive images that have an overlapping area and being similarly atmospheric corrected provide similar LAI estimates. Our results show that the overlaying area reveals small mean absolute differences of $0.1(\max =0.8)$ for $\mathrm{LAI}_{\mathrm{NDVI}}, 0.1$ $(\max =0.6)$ for $\mathrm{LAI}_{\mathrm{SAVI}}$ and $0.1(\mathrm{max}=0.6)$ for $\mathrm{LAI}_{\mathrm{SARVI}}$. LAI uncertainty depends on satellite viewing constellations during image capture, which is intensified by the ATCOR model algorithm centre coordinate approach. The variability of LAI estimated from SARVI was smallest for most of the images of the time-series. Considering the mean LAI absolute differences of 0.1 , we can conclude that mosaicking of image pairs is possible for jointly usage as SVAT model input.

Both investigations revealed that model sensitivity to LAI variations is higher in areas with lower LAI than for areas with larger LAI (dense vegetation). Therefore, SVAT modellers should take particular care when performing atmospheric correction parameterisation in these areas. The LAI uncertainties $( \pm 0.2)$ that typically occurred at our study site result in small (transpiration $\pm 1.4 \%$, ET $\pm 1.7 \%$ ) to medium (interception $\pm 4.9 \%$, evaporation \pm 6.4 ) prediction uncertainties in SVAT modelling. These model uncertainties are assumed to be still 
acceptable for most SVAT model applications, such as agricultural management.

Conclusively, SVAT model sensitivity to LAI is ranked from lowest to highest as: $\mathrm{ET} \approx$ transpiration < interception < evaporation for CoupModel. Assuming that the SVAT model uncertainties of $<5 \%$ are acceptable, then the LAI uncertainty due to atmospheric correction should be kept $<0.2$, in order to assure that we achieve usable SVAT model results.

\section{Acknowledgements}

This research was funded by the IPSWAT (International Postgraduate Studies in Water Technologies) scholarship program, an initiative of the Federal Ministry of Education and Research (BMBF). Furthermore, this work was kindly supported by Helmholtz Impulse and Networking Fund through Helmholtz Interdisciplinary Graduate School for Environmental Research (HIGRADE). We sincerely thank DLR for providing data from the RapidEye Science Archive (RESA) and RapidEye AG. We thank Bernd Fichtelmann for his expertise and support. Special thanks to native English speaker Christopher Higgins for proofreading this text.

\section{References}

DLR, \& Blackbridge AG (2012). RapidEye Science Archive (RESA). DLR \& Blackbridge AG. Arora, V. K. (2002). Modelling vegetation as a dynamic component in soil-vegetation-atmosphere-transfer schemes and hydrological models. Reviews of Geophysics, 40(2), 1006-1032.

Asner, G. P., Scurlock, J. M.O., \& Hicke, J. A. (2003). Global synthesis of leaf area index observations: Implications for ecological and remote sensing studies. Global Ecology and Biogeography, 12, 191-205.

Baret, F., Jacquemoud, S., \& Hanocq, J. F. (1993). About the soil line concept in remote sensing. Advances in Space Research, 13(5), 281-284.

Bréda, N. J. J. (2003). Ground-based measurements of leaf area index: A review of methods, instruments and current controversies. Journal of Experimental Botany, 54(392), 2403-2417

Cermák, J., Kucera, J., Bauerle, W. L., Phillips, N., \& Hinckley, T. M. (2007). Tree water storage and its diurnal dynamics related to sap flow and changes in stem volume in oldgrowth Douglas-fir trees. Tree Physiology, 27(2), 181-198.

Cutini, A., Matteucci, G., \& Mugnozza, G. S. (1998). Estimation of leaf area index with the Li-Cor LAI 2000 in deciduous forests. Forest Ecology and Management, 105(1-3), $55-65$

Du, H., Fan, W., Zhou, G., Xu, X., Ge, H., Shi, Y., et al. (2011). Retrieval of canopy closure and LAI of Moso bamboo forest using spectral mixture analysis based on real scenario simulation. Simulation, 49(11), 4328-4340.

Embaye, K., Weih, M., Ledin, S., \& Christersson, L. (2005). Biomass and nutrient distribution in a highland bamboo forest in southwest Ethiopia: Implications for management. Forest Ecology and Management, 204(2-3), 159-169.

Embrapa (2006). Sistema Brasileiro de classificação de solos. (2nd ed.). Brasília: Embrapa-SPI - Centro Nacional de Pesquisa de Solos.

ERDAS, \& Geosystems (2011). ATCOR for ERDAS IMAGINE 2011 - Haze reduction, atmospheric and topographic correction - User manual ATCOR 2 and ATCOR 3. ERDAS Imagine (pp. 1-226). ERDAS-GeoSystems.

Ghanbarian-Alavijeh, B., Liaghat, A., Huang, G. -H., \& Van Genuchten, M. T. (2010). Estimation of the van Genuchten soil water retention properties from soil textural data. Pedosphere, 20(4), 456-465.

Glenn, E. P., Huete, A.R., Nagler, P. L., \& Nelson, S. G. (2008). Relationship between remotely-sensed vegetation indices, canopy attributes, and plant physiological processes: What vegetation indices can and cannot tell us about landscape. Sensors, 8 , 2136-2160.

Guanter, L., Richter, R., \& Kaufmann, H. (2009). On the application of the MODTRAN4 atmospheric radiative transfer code to optical remote sensing. International Journal of Remote Sensing, 30, 1407-1427.

Haboudane, D. (2004). Hyperspectral vegetation indices and novel algorithms for predicting green LAI of crop canopies: Modeling and validation in the context of precision agriculture. Remote Sensing of Environment, 90(3), 337-352.

Hadjimitsis, D. G., Papadavid, G., Agapiou, A., Themistocleous, K., Hadjimitsis, M. G., \& Retalis, A. (2010). Atmospheric correction for satellite remotely sensed data intended for agricultural applications: Impact on vegetation indices. Natural Hazards and Earth System Sciences, 89-95.

Holzer-Popp, T., Bittner, M., Borg, E., Dech, S., Erbertseder, T., Fichtelmann, B., et al. (2002) Process for correcting atmospheric influences in multispectral optical remote sensing. (Patent number UP 6484099).

Horn, J., \& Schulz, K. (2010). Post-processing analysis of MODIS leaf area index subsets. Journal of Applied Remote Sensing, 4(1), 043557.
Huete, A.R. (1988). A soil-adjusted vegetation index (SAVI). Remote Sensing of Environment, 25, 295-300.

Huete, A.R., Liu, H. Q., Batchily, K., \& van Leeuwen, W. (1997). A comparison of vegetation indices over a global set of TM images for EOS-MODIS. Remote Sensing of Environment, $59,440-451$

ICEA (2013). Sistema de geração e disponibilização de informações climatológicas [Climate data of airport Salvador (Bahia)]. (Retrieved September 06, 2013, from http://clima. icea.gov.br).

Jansson, P. -E., \& Karlberg, L. (Eds.). (2010). CoupModel manual - Coupled heat and mass transfer model for soil-plant-atmosphere systems. Stockholm: KTH (Retrieved January 12, 2013, from http://www2.lwr.kth.se/CoupModel/NetHelp/).

Jarvis, A., Reuter, H. I., Nelson, A., \& Guevara, E. (2008). Hole-filled seamless SRTM data V4. International Centre for Tropical Agriculture (CIAT), USGS/NASA. http://srtm.csi.cgiar. org (Retrieved from)

Kaufman, J. Y. \& Tanré, D. (1992). Atmospherically resistant vegetation index (ARVI) for EOS-MODIS. IEEE Transactions on Geoscience and Remote Sensing, 30(2), 261-270.

Kergoat, L. (1998). A model for hydrological equilibrium of leaf index on a global scale. Journal of Hydrology, 268-286 (212-213).

Kerr, J. T., \& Ostrovsky, M. (2003). From space to species: Ecological applications for remote sensing. Trends in Ecology \&' Evolution, 18(6), 299-305.

Kottek, M., Grieser, J., Beck, C., Rudolf, B., \& Rubel, F. (2006). World map of Köppen-Geiger climate classification (updated with CRU TS 2.1 temperature and VASClimO v1.1 precipitation data 1951 to 2000). Meteorologische Zeitschrift, 15(3), 259-263.

Lenhart, T., Eckhardt, K., Fohrer, N., \& Frede, H. -G. (2002). Comparison of two different approaches of sensitivity analysis. Physics and Chemistry of the Earth, 27, 645-654.

Liu, H. Q., \& Huete, A. (1995). A feedback based modification of the NDVI to minimise canopy background and atmospheric noise. Transactions on Geoscience and Remote Sensing, 33(2), 457-465.

Mannschatz, T. \& Dietrich, P. (2013). Uncertainties of LAI estimation from satellite images due to atmospheric correction (Project ID: 502). In E. Borg, H. Daedelow, \& R. Johnson (Eds.), From the basics to the service: Proceedings of the 5th RESA-Workshop - 20-21 March 2013 Neustrelitz (pp. 271-290). Berlin: GITO-Verl.

Metselaar, K., van Dam, J. C., \& Feddes, R. A. (2006). Screening and understanding the importance of soil hydrology related factors in a SVAT scheme - Reports in the framework of the KvR project CS3. Wageningen Institute for Environment and Climate Research (Retrieved from http://library.wur.nl/WebQuery/wurpubs/403571).

Miura, T., Heute, A.R., Yoshioka, H., \& Holben, B. N. (2001). An error and sensitivity analysis of atmospheric resistant vegetation indices derived from dark target-based atmospheric correction. Remote Sensing of Environment, 78, 284-298.

Monteith, J. L. (1965). Evaporation and environment. In G. E. Fogg (Ed.), Symposium of the Society for Experimental Biology, The state and movement of water in living organisms (pp. 205-234) (19th ed.). New York: Academic Press.

Pettorelli, N., Vik, J. O., Mysterud, A, Gaillard, J. -M., Tucker, C. J. \& Stenseth, N. C. (2005). Using the satellite-derived NDVI to assess ecological responses to environmental change. Trends in Ecology \& Evolution, 20(9), 503-510.

RapidEye (2012). RapidEye ${ }^{\mathrm{TM}}$ image product specification. http://www.rapideye.com/ products/basic.htm (Retrieved from)

Richardson, A. J., \& Wiegand, C. L. (1977). Distinguishing vegetation from soil background information. Photogrammetric Engineering and Remote Sensing, 43, 1541-1552.

Richter, R. (1996). A spatially adaptive fast atmospheric correction algorithm. International Journal of Remote Sensing, 17(6), 1201-1214.

Richter, R. (2013). Conversion factors between visibility and aerosol optical thickness (AOT). Personal communication.

Richter, R., \& Schläpfer, D. (2013). Atmospheric and topographic correction for satellite imagery (ATCOR 2/3 user guide, version 8.2.1) (p. 224). Wil, Switzerland: ReSe Application Schläpfer.

Richter, R., Schläpfer, D., \& Müller, A. (2006). An automatic atmospheric correction algorithm for visible/NIR imagery. International Journal of Remote Sensing, 27(10), 2077-2085

Rouse, J. W., \& Haas, R. H. (1973). Monitoring vegetation systems in the Great Plains with ERTS. 3rd ERTS Symposium NASA SP-351 (pp. 309-317). Washington: U.S. Gov.

Van Gorsel, E., Kljun, N., Leuning, R., Berni, J. A. J., Cabello-Leblic, A., Held, A., et al. (2011). Use of high resolution Lidar and hyperspectral data to evaluate the sensitivity of net ecosystem exchange to stand structural and plant chemical properties. 34th International Symposium on Remote Sensing of Environment (pp. 1-4). Sydney, Australia.

Verrelst, J., Schaepman, M. E., Koetz, B., \& Kneubühler, M. (2008). Angular sensitivity analysis of vegetation indices derived from CHRIS/PROBA data. Remote Sensing of Environment, 112(5), 2341-2353.

Viña, A., Gitelson, A. A., Nguy-Robertson, A. L., \& Peng, Y. (2011). Comparison of different vegetation indices for the remote assessment of green leaf area index of crops. Remote Sensing of Environment, 115(12), 3468-3478.

Wiegand, C. L., \& Richardson, A. J. (1990). Use of spectral vegetation indices to infer leaf area, evapotranspiration and yield: I. Rationale. Agronomy Journal, 82(3), 623-629.

WMO (2013). Climate and monitoring data. http://www.wmo.int (Retrieved from)

Yao, Y., Liu, Q., \& Li, X. (2008). LAI retrieval and uncertainty evaluations for typical rowplanted crops at different growth stages. Remote Sensing of Environment, 112(1), 94-106.

Zheng, G., \& Moskal, L. M. (2009). Retrieving leaf area index (LAI) using remote sensing: Theories, methods and sensors. Sensors, 9(4), 2719-2745. 